\title{
Advance Methodologies for Pharmaceutical Salt Synthesis
}

\author{
2 Md Sadeque Hossain Mithu, Sophia Economidou, Vivek Trivedi, Saumil Bhatt, and Dennis Douroumis*
}

Cite This: https://dx.doi.org/10.1021/acs.cgd.0c01427

Read Online

3 ABSTRACT: Pharmaceutical salt formation is the most preferred 4 and effective method to enhance the physicochemical properties of 5 an active pharmaceutical ingredient (API) such as solubility, 6 bioavailability, stability, and processability. Salts are defined as 7 crystalline materials composed of two or more different molecules, 8 typically, drug and salt formers in the same crystal lattice, where 9 the components in the crystal lattice are in an ionized state and 10 interact via ionic interactions. Conventionally, the solvent11 mediated process is used to manufacture the salts, where the use 12 of a vast amount of solvent has a detrimental effect on the 13 environment. Recently, there are very few methods that are being 14 reported as solvent-free to manufacture the pharmaceutical salt. In 15 this review, recent trends and advances in synthesis and 16 manufacturing of salts are reviewed. Furthermore, the operational principles of commonly employed salt manufacturing 17 technologies are discussed including their benefits and drawbacks in terms of purity, stability, throughput, and limitations in large18 scale production. The final section is devoted to reviewing the regulatory issues in terms of the patent application for the salt form of 19 an API compared to other multicomponent forms.

\section{INTRODUCTION}

20 Poor physicochemical properties prohibiting active pharma21 ceutical ingredients (APIs) from being readily utilizable in 22 formulation development are a common drawback in the 23 pharmaceutical industry. Currently, numerous drug substances 24 suffer from low aqueous solubility, resulting in poor 25 bioavailability, ${ }^{1,2}$ while similarly, more than $60 \%$ of new drug 26 molecules bear low solubility due to their increased size 27 (molecular weight) and lipophilicity. ${ }^{3-5}$ Newly introduced 28 APIs in particular, commonly suffer from significant drawbacks 29 pertaining to their physicochemical properties, namely, 30 solubility, bioavailability, crystallinity, thermal stability, flow 31 properties, etc. Such issues introduce additional risks of not 32 attaining effective clinical outcomes and increasing associated 33 costs, hence disfavoring investments in new drugs by 34 pharmaceutical companies. ${ }^{6,7}$ Efforts to tackle this challenge 35 have been increasingly focused on the use of the salt forms of 36 APIs, whereby the use of strong counterions for both anionic 37 and cationic drugs has been exploited as a solution for more 38 than three decades. A number of approaches including the 39 synthesis of multicomponent drug products using pharma40 ceutically acceptable coformers/counterions are being actively 41 studied by various research groups worldwide. ${ }^{7,8}$ The APIs can 42 exist in various solid forms, the nature of which is of eminent 43 importance in relation to industrial scale-up and pharmaco44 logical activity. ${ }^{9}$ As shown in Figure 1, the main forms are 45 amorphous and crystalline with the latter being the preferred

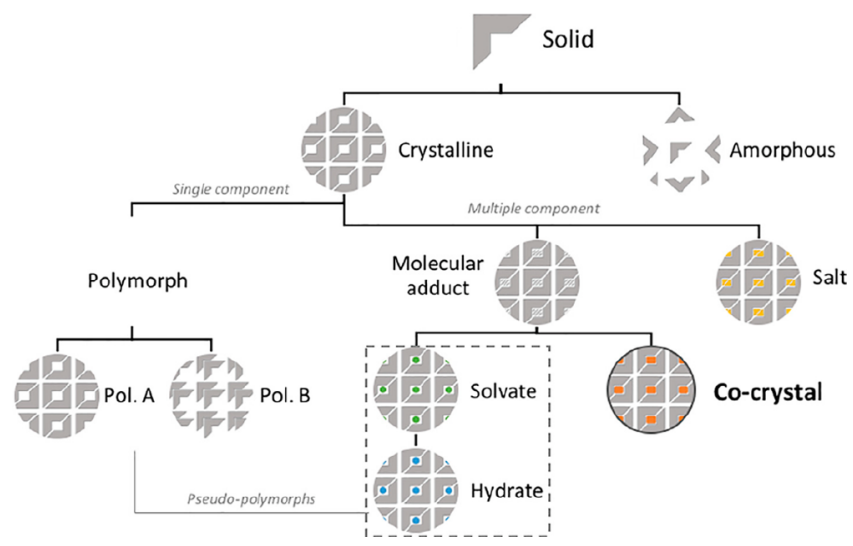

Figure 1. Diversity of solid forms in which an API can exist. ${ }^{9}$ Adapted with permission from ref 9. Copyright 2012 American Chemical Society.

option for the pharmaceutical industry. Crystalline materials 46 present better stability, and are easier to process and purify, but 47

Received: October 20, 2020 
48 in many cases the low water solubility is a major disadvantage. 49 Nevertheless, different solid forms of APIs such as polymorphs, 50 amorphous, hydrates, solvates, salts, cocrystals, and coordina51 tion compounds can improve the physicochemical properties 52 of drug molecules ${ }^{6}$ including water solubility and dissolution 53 without affecting their pharmacological activity. ${ }^{10}$

54 The solid dosage forms, in particular, comprise the majority 55 of common formulations $(65-70 \%)$ in the pharmaceutical 56 industry, due to being easily self-administered and thus highly 57 patient compliant. The crystalline states of solid APIs are 58 preferred, owing to their "relatively easy" synthesis, higher 59 stability, and low levels of impurities. 7,11 Consequently, crystal 60 engineering has become an emerging technology for drug 61 development, having attracted the attention of a large body of 62 researchers. Evidently, it is difficult to modify single63 component crystals in order to attain the desired properties, 64 as they are very much limited to polymorphs, wherein subtle 65 changes in their physicochemical properties are only 66 possible. $^{12,13}$ This is why the synthesis of multicomponent 67 systems has become a preferred route to obtain sought-after 68 properties in APIs, necessary to achieve required formulation 69 attributes. While crystal engineering has indeed simplified the 70 synthesis of multicomponent APIs including salts and 71 cocrystals, determining which specific solid form of an API is 72 suitable for further processing, scale-up, formulation, and 73 clinical trials is critical. ${ }^{7,9}$

\section{PHARMACEUTICAL SALTS TO IMPROVE SOLUBILITY}

75 Pharmaceutical salts, which can be prepared using an 76 appropriate counterion of an API, are undoubtedly the most 77 common multicomponent systems, regularly used for improv78 ing the aqueous solubility of APIs. In cases wherein the salt 79 formation is not feasible, cocrystal formation can be the best 80 alternative to enhance the solubility and other physicochemical 81 properties of the drug. ${ }^{5-7}$

82 According to IUPAC, a salt is a "chemical compound 83 consisting of an assembly of cations and anions". ${ }^{14} \mathrm{~A}$ 84 pharmaceutical salt can be synthesized from an ionizable API 85 (anionic, cationic, and zwitterionic) and an opposite charged 86 ion, either molecular (acetate, mesylate) or atomic (sodium, 87 bromide). ${ }^{7}$ According to the FDA, salts are classified as "any of 88 numerous compounds that result from replacement of part or 89 all of the acid hydrogen of an acid by a metal or a radical acting 90 like a metal; an ionic or electrovalent crystalline compound" 91 (FDA guidelines 2018). ${ }^{15}$

92 In the last 60 years, salt formation has been employed as one 93 of the most prominent methods to enhance drug properties. 94 Notably, more than $50 \%$ of marketed drug products are in the 95 form of salts. ${ }^{7,16,17}$ The pharmaceutical industry has extensively 96 utilized salt formation as an attractive approach to improve the 97 solubility of poorly water-soluble drugs, due to the process 98 simplicity and stability of salts resulting from ionizable drugs. ${ }^{18}$ 99 Moreover, salts enhance the dissolution rate rather than the 100 solubility of the API itself, leading to improved bioavail101 ability. ${ }^{16,17}$

102 The aqueous solubility of drugs, classified as weakly acidic or 103 basic, is dependent on $\mathrm{pH}$ and governed by the ionization and 104 dissociation constant as described by the Henderson105 Hasselbalch equation. ${ }^{17,19,20}$ The $\mathrm{pH}$ dependent solubility of 106 a weak base can have two distinct profiles based on whether 107 the free base or the salt is the equilibrium species except at the
$\mathrm{pH}$ of the highest solubility $\left(\mathrm{pH}_{\max }\right)$. The total solubility of a 108 base can be presented as

$$
\mathrm{S}=\left[\mathrm{BH}^{+}\right]+[\mathrm{B}]
$$

where $\mathrm{S}\left[\mathrm{BH}^{+}\right]$and $[\mathrm{B}]$ represent the total solubility, ionized 111 and un-ionized base, respectively. The equilibrium for a 112 monobasic base, when dissolved in water, can be written as 113

$$
\mathrm{BH}^{+}+\mathrm{H}_{2} \mathrm{O} \stackrel{K_{2}}{\leftrightarrow} \mathrm{B}+\mathrm{H}_{3} \mathrm{O}
$$

Equation 2 can be rearranged to calculate the ionization 115 constant $\left(k_{\mathrm{a}}\right)$ :

$$
K_{\mathrm{a}}=\frac{[\mathrm{B}]\left[\mathrm{H}_{3} \mathrm{O}^{+}\right]}{\left[\mathrm{BH}^{+}\right]}
$$

As stated above, the solubility of the salts is greatly influenced 118 by the $\mathrm{pH}$ of the dissolution media. The solubility of salt at $\mathrm{pH} 119$ higher than $\mathrm{pH}_{\max }$ can be described as the solubility of the free 120 base, as follows:

$$
\mathrm{S}=\mathrm{S}_{0}\left(1+\left[\mathrm{H}_{3} \mathrm{O}^{+}\right] /\left[K_{\mathrm{a}}\right]\right)
$$

where $S_{0}$ and $S$ are the intrinsic (solubility of the un-ionized 123 form) solubility and total solubility, respectively.

Similarly, the solubility at $\mathrm{pH}$ lower than the $\mathrm{pH}_{\max }$ is 125 defined as

$$
\mathrm{S}=\sqrt{K_{\mathrm{sp}}}\left(1+\left[K_{\mathrm{a}}\right] /\left[\mathrm{H}_{3} \mathrm{O}^{+}\right]\right)
$$

where $K_{\mathrm{sp}}\left(\left[\mathrm{BH}^{+}\right]\left[\mathrm{A}^{-}\right]\right)$is the solubility product of the salt. 128

The relationship between $\mathrm{pH}_{\max }, \mathrm{p} K_{\mathrm{a}}$, total solubility $\left(\mathrm{S}_{0}\right), 129$ and solubility product $\left(K_{\mathrm{sp}}\right)$ is represented by the following 130 equations:

$$
\begin{aligned}
& \text { Weak bases: } \mathrm{pH}_{\max }=\mathrm{p} K_{\mathrm{a}}+\log \mathrm{S}_{0} / \sqrt{K_{\mathrm{sp}}} \\
& \text { Weak acids: } \mathrm{pH}_{\max }=\mathrm{p} K_{\mathrm{a}}-\log S_{0} / \sqrt{K_{\mathrm{sp}}}
\end{aligned}
$$

The $\mathrm{pH}_{\max }$ value is essential for the determination of the $\mathrm{pH}$ at 134 which the salt attains its maximum solubility, as well as to 135 estimate the stability of the salt in comparison to the free base, 136 as a function of $\mathrm{pH}$ (Figure 2). The $\mathrm{pH}_{\max }$ and $\mathrm{pK}$ are directly $137 \mathrm{f} 2$ proportional; hence, an increase of the $\mathrm{p} K_{\mathrm{a}}$ leads to an 138 analogous increase of the $\mathrm{pH}_{\max }$ for a weak base. On the 139 contrary, an increase of the salt solubility, or $\sqrt{K_{\mathrm{sp}}}$, will result 140 in a decrease of the $\mathrm{pH}_{\max }$ due to their inverse relationship as 141 presented in eq 7. Therefore, it is expected that the $\mathrm{pH}_{\max }$ will 142 change significantly based on the choice of counterions. ${ }^{16,17,20} 143$

The main prerequisite for salt formation is the ionizability of 144 the API, to enable the interaction with the desired anion or 145 cation. In general, salts are highly stable, but they can also exist 146 as hydrates, which may compromise the stability and be proven 147 problematic during secondary processing steps. The formation 148 of hydrates can be difficult to monitor and control during wet 149 massing, fluid bed drying, and aqueous film coating., ${ }^{5,21,22} 150$ Similarly, it has been documented that salts containing 151 chloride ions (54\% of the salts approved between 1995 and 152 2006) might exhibit reduced dissolution rates due to the 153 common ion effect, as gastric and intestinal fluids (jejunum) 154 are rich in chloride. ${ }^{8,16}$ Salts are an excellent way for enhancing 155 the pharmacological properties of a drug, but the sole focus on 156 the improvement of dissolution rate and solubility properties 157 of drugs can sometimes be counterproductive. This is of 158 


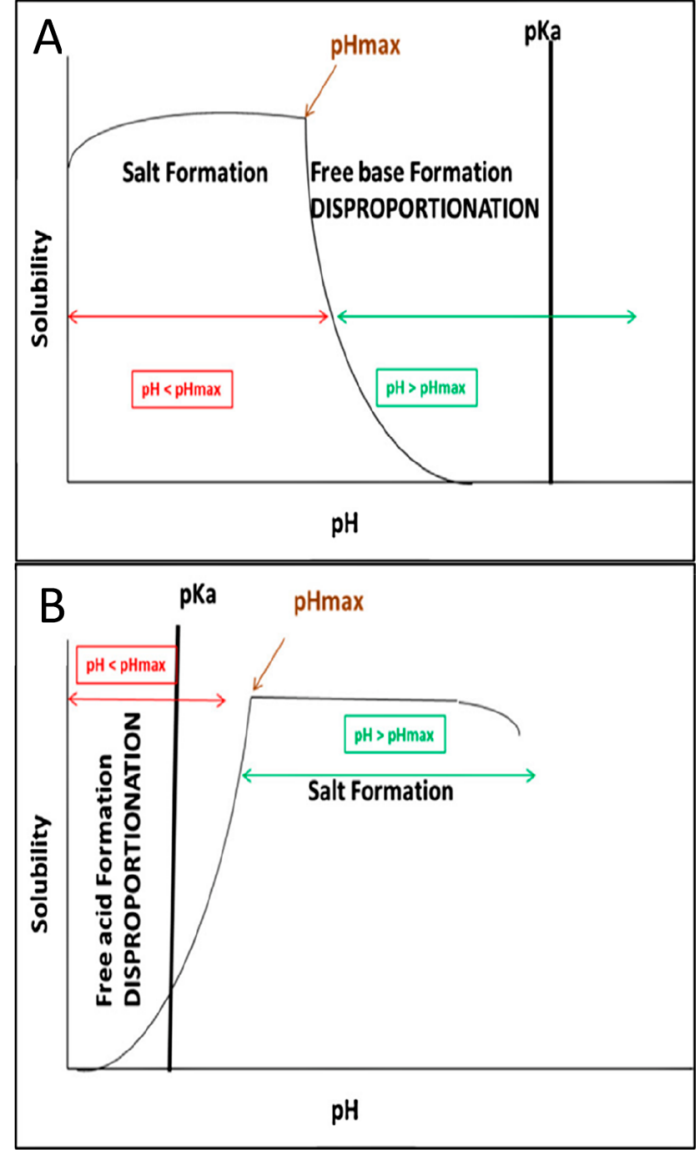

Figure 2. Schematic depiction of the $\mathrm{pH}$-solubility profiles of (A) weakly basic drug, and (B) weakly acidic drug. In both the profiles, solubility may be expressed by two independent curves viz. when $\mathrm{pH}$ $<\mathrm{pH}_{\max }$ and when $\mathrm{pH}>\mathrm{pH}_{\max }$. The point where these two curves meet is the $\mathrm{pH}_{\max }$. Sometimes a drop in solubility near the lower $\mathrm{pH}$ in curve " $\mathrm{A}$ " and a higher $\mathrm{pH}$ in curve " $\mathrm{b}$ " is observed due to the common ion effect. ${ }^{16,19}$

159 particular importance as this improvement can occasionally 160 lead to adverse effects by increasing the accumulation of the 161 drug beyond the equilibrium solubility, if not considered 162 carefully. $^{23}$

163 Among numerous options, cocrystals (Figure 3) have 164 opened a new door in relation to drug development as they 165 are not limited, unlike salts, to ionizable drugs. Furthermore, 166 cocrystals formation can be an effective approach to create new 167 intellectual property in the pharmaceutical industry and thus 168 prolong the life cycle of APIs. ${ }^{25}$

169 For nonionizable drugs and compounds, the salt formation 170 of which is not possible, cocrystallization is a possible 171 alternative for drug development. Although cocrystals have 172 not yet gained a significant market share due to challenges 173 related to their recognition as new APIs, the prospects are 174 definitely promising. $7,24,26$

175 Albeit solubility is the predominant concern in drug 176 development, a choice needs to be made between the highest 177 solubility and the highest stability. This becomes a particular 178 challenge in cases when the maximum soluble form suffers 179 from stability issues due to, e.g., hydrolysis, which is a common 180 degradation problem. .,8,23 $^{\text {. }}$

181 Another common approach entails the application of 182 amorphous solids in drug products; however, crystalline drug

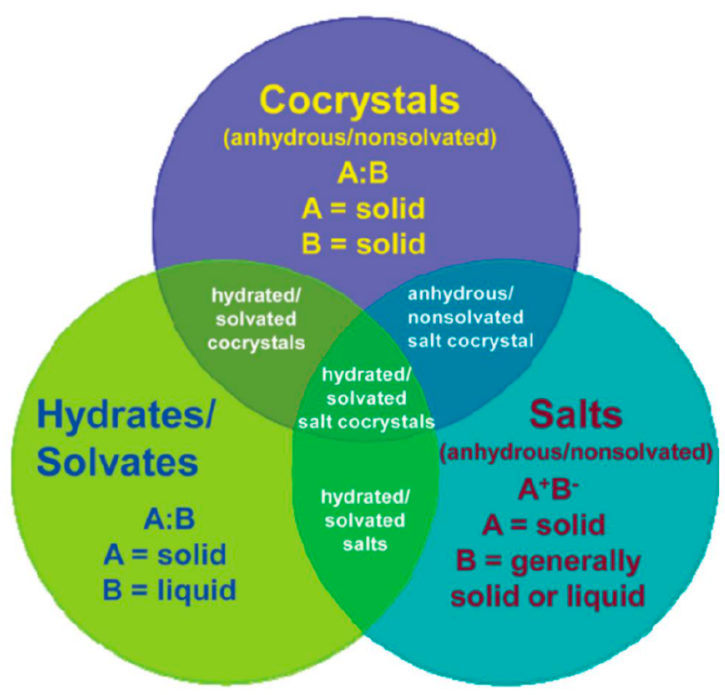

Figure 3. Different multicomponent formation: cocrystals, salts, hydrates/solvates. ${ }^{24}$ Reprinted from ref 24 with permission. Copyright 2017 Elsevier.

materials are preferred to meet the requirements in terms of 183 thermodynamic properties such as purity, stability, and means 184 of processing. ${ }^{12}$ Furthermore, for systems including solvates, 185 hydrates, and inclusion compounds, physical stability is an 186 important factor to consider since hydrates are considered a 187 nemesis for crystal engineering due to the "promiscuity" of 188 water. $^{27}$ Amorphous solids can show low thermal stability, and 189 this often works against their desired use in drug materials. 190 Solvates may show instability due to a rise in temperature and 191 humidity that can possibly limit their selection as drug 192 products. $^{12}$ Generally, hydrates/solvates are less soluble and 193 more stable than the corresponding nonsolvated forms in a 194 specified solvent. The solubility of hydrates or solvates 195 decreases in relation to the increasing numbers of solvent 196 molecules within the crystal lattice. ${ }^{5,8,28}$ Therefore, salts are 197 still the most recognized and widely accepted form of 198 alteration to a drug molecule in the pharmaceutical industry, 199 to obtain desired physicochemical properties leading to the 200 development of formulations with optimal specifications. The 201 critical factor in the development of salts is the choice of the 202 salt former, which needs to be selected depending on the 203 physicochemical properties and toxicological and pharmaco- 204 logical consequences of the counterion.

205

2.1. Pharmaceutical Salt Formers. The salt formation of 206 an API largely depends on the acidity or basicity of the API 207 itself, the safety of the salt former/counterion, the choice of 208 dosage forms, the route of administration, and the drug 209 indications. $^{29,30}$ The salt formers/counterions can be divided 210 into two categories (Table 1) based on their purpose and $211 \mathrm{t} 1$ functionality.

In most cases, hydrochloride salts have been commonly 213 employed to develop salts of weakly basic drug substances. ${ }^{31} 214$ However, the use of hydrochloride salts had to be restricted 215 due to the unacceptability of high acidity in formulations, the 216 risk of corrosion, and poor stability of the acid labile and 217 hygroscopic drugs. ${ }^{29,31}$ The popularity of chloride as the 218 counterion until the end of the 20th century in both oral and 219 injectable dosage forms was high, although the growth in the 220 usage of chloride salts clearly dropped since the beginning of 221 the current century. Nonetheless, they still remain ubiquitous, 222 
Table 1. List of Counterions Used in Salt Formation ${ }^{36}$

\begin{tabular}{|c|c|c|c|}
\hline acidic counterion & $\mathrm{p} K_{\mathrm{a} 1}$ & $\mathrm{p} K_{\mathrm{a} 2}$ & $\mathrm{p} K_{\mathrm{a} 3}$ \\
\hline acetic & 4.76 & & \\
\hline benzoic & 4.20 & & \\
\hline citric & 3.13 & 4.76 & 6.40 \\
\hline D,L-lactic & 3.86 & & \\
\hline fumaric & 3.03 & 4.38 & \\
\hline glutamic & 2.19 & 9.67 & \\
\hline hydroiodic & -8 & & \\
\hline hydrochloride & -6 & & \\
\hline hydrobromic & -6 & & \\
\hline $\mathrm{L}-(+)$-tartaric & 3.02 & 4.36 & \\
\hline malic & 3.40 & 5.03 & \\
\hline maleic & 1.92 & 6.23 & \\
\hline methane sulfonic & -1.2 & & \\
\hline nitric & -1.32 & & \\
\hline oleic & 5.02 & & \\
\hline oxalic & 1.25 & 4.28 & \\
\hline pamoic & 2.51 & 3.1 & \\
\hline phosphoric & 1.96 & 7.12 & 12.32 \\
\hline$p$-toluene sulfonic & -1.34 & & \\
\hline salicylic & 2.98 & 13.4 & \\
\hline succinic & 4.19 & 5.48 & \\
\hline sulfuric & -3 & 1.92 & \\
\hline basic counterion & $\mathrm{p} K_{\mathrm{al}}$ & $\mathrm{p} K_{\mathrm{a} 2}$ & $\mathrm{p} K_{\mathrm{a} 3}$ \\
\hline aluminum & 5.0 & & \\
\hline ammonium & 9.27 & & \\
\hline $\mathrm{L}$-arginine & 13.2 & 9.09 & 2.18 \\
\hline calcium & 12.7 & & \\
\hline chloroprocaine & 8.7 & & \\
\hline choline & 13.9 & & \\
\hline diethylamine & 10.93 & & \\
\hline diethanolamine & 8.96 & & \\
\hline ethanolamine & 9.5 & & \\
\hline ethylenediamine & 9.69 & & \\
\hline histidine & 1.82 & 9.17 & \\
\hline L-lysine & 10.79 & 9.18 & 2.16 \\
\hline magnesium & 11.4 & & \\
\hline meglumine & 8.03 & & \\
\hline potassium & 14 & & \\
\hline procaine & 9.0 & & \\
\hline sodium & 14 & & \\
\hline tromethamine & 8.02 & & \\
\hline triethylamine & 10.75 & & \\
\hline zinc & $9^{37}$ & & \\
\hline
\end{tabular}

223 albeit succinates, acetates, and bromides have gained increasing

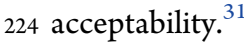

225 2.2. Prerequisites for Salt Formation. For a poorly 226 bioavailable API, salt formation is often the first approach 227 considered in industry, in view of the fact that salts are likely to 228 be stable due to the presence of ionic bonds as well as be more 229 soluble than the un-ionized form. ${ }^{32,33}$ API crystallinity/ 230 solubility and whether solubility is the limiting factor are the 231 primary criteria that need to be meticulously considered during 232 the high-throughput multicomponent crystalline product (salt, 233 cocrystal etc.) screening. ${ }^{34}$

234 Depending on the various stoichiometric molar ratios of API 235 and counterion, multicomponent products such as salts can 236 exhibit different physicochemical properties due to the distinct 237 arrangements of molecules. ${ }^{35}$ Moreover, different molecular 238 entities consisting of different molar ratios of API and coformers can be treated as new products, yielding new 239 patents. For this reason, increased attention should be paid to 240 the molar ratio of API and counterion during the synthesis of 241 multicomponent products. ${ }^{18}$

242

Salt formation occurs when an ionized compound forms a 243 strong ionic bond with the oppositely charged counterions in a 244 solution. The $\mathrm{p} K_{\mathrm{a}}$ rule governs the development of multi- 245 component systems, and the difference between $\Delta \mathrm{p} K_{\mathrm{b}}$ and $\mathrm{p} K_{\alpha} 246$ indicates whether the salt formation is possible. The respective 247 equation is shown below:

$$
\Delta \mathrm{p} K_{\mathrm{a}}=\mathrm{p} K_{\mathrm{b}}-\mathrm{p} K_{\mathrm{a}}
$$

From the above equation, high $\Delta \mathrm{p} K_{\mathrm{a}}$ values provide a strong 250 indication of salt formation. ${ }^{8}$ It is known that at $\Delta \mathrm{p} K_{\mathrm{a}}<-1,251$ mostly cocrystals are formed, while salts are formed exclusively 252 when $\Delta \mathrm{p} K_{\mathrm{a}}>4$ (Figure 4). ${ }^{38}$ The foregoing has been applied $253 \mathrm{f} 4$ to various drug/coformer pairs; however, the outcome of a 254 $\Delta \mathrm{pK}_{\mathrm{a}}$ at a range between 0 and 3 remains hard to predict. 255

Typically, the difference of the $\mathrm{p} K_{\mathrm{a}}$ values gives an initial 256 indication during multicomponent screening; ${ }^{39}$ nevertheless, 257 other factors such as particle size, solubility, potency, etc. 258 should be also considered, as $\mathrm{p} K_{\mathrm{a}}$ is usually evaluated with 259 regard to water but not in the solid state, and it is temperature 260 dependent. ${ }^{7,32,33}$ Furthermore, pharmaceutical salt formation 261 fully depends on proton transfer, so validating whether proton 262 transfer between two components is possible is an essential 263 prerequisite for salt screening. The proton transfer capabilities 264 can be easily ascertained after calculating the difference 265 between the acid dissociation constants for the hydrogen 266 bond donors and the conjugate base of the hydrogen bond 267 acceptor. $^{32,33}$

A hydrogen bond will be formed without undergoing proton 269 transfer if a negative value is returned from eq 8 . However, 270 proton transfer will take place along with a stronger double 271 charge assisted hydrogen bond, if a positive value is obtained. 272 Pharmaceutical salts can be mainly formed via hydrogen 273 bonding $^{40}$ (Figure 5) in supramolecular synthons. Two types $274 \mathrm{fs}$ of supramolecular synthons are available: supramolecular 275 homosynthons between the same complementary functional 276 groups (e.g., carboxylic acid dimers) and supramolecular 277 heterosynthons between different but complementary func- 278 tional groups (e.g., carboxylic acid-amide). Different supra- 279 molecular homo- or heterosynthons include carboxylic acid- 280 amide, carboxylic acid-aromatic nitrogen, alcohol-aromatic 281 nitrogen, and alcohol-amine (Figure 6). ${ }^{12}$

Martin et al, 2013 reported the salt and cocrystal formation 283 of a basic drug, ketoconazole, having a $\mathrm{p} K_{\mathrm{a}}$ value of 7.47, 284 formed cocrystals with fumaric acid, succinic acid, adipic acid, 285 and a salt with oxalic. ${ }^{10}$

The $\mathrm{p} K_{\mathrm{a}}$ difference between ketoconazole and oxalic acid is 287 higher than 3, which, according to the $\mathrm{p} K_{\mathrm{a}}$ rule, indicates that 288 salt formation was expected. Furthermore, the $\mathrm{p} K_{\mathrm{a}}$ difference of 289 succinic and adipic acid with ketoconazole is less than 3290 rendering salt formation unexpected, leading to the formation 291 of the cocrystal. On the contrary, the $\mathrm{p} K_{\mathrm{a}}$ difference between 292 ketoconazole and fumaric acid was higher than 3 prompting 293 the assumption that salt will be formed; however, the end 294 product was a cocrystal due to the absence of proton transfer 295 between the molecules. Hence, the $\mathrm{p} K_{\mathrm{a}}$ rule is not applicable in 296 all cases where proton transfer also depends on the availability 297 of proton donor and acceptor.

298

In recent years, modern drug discovery and drug develop- 299 ment tools have been employed to reduce the cost in this 300 


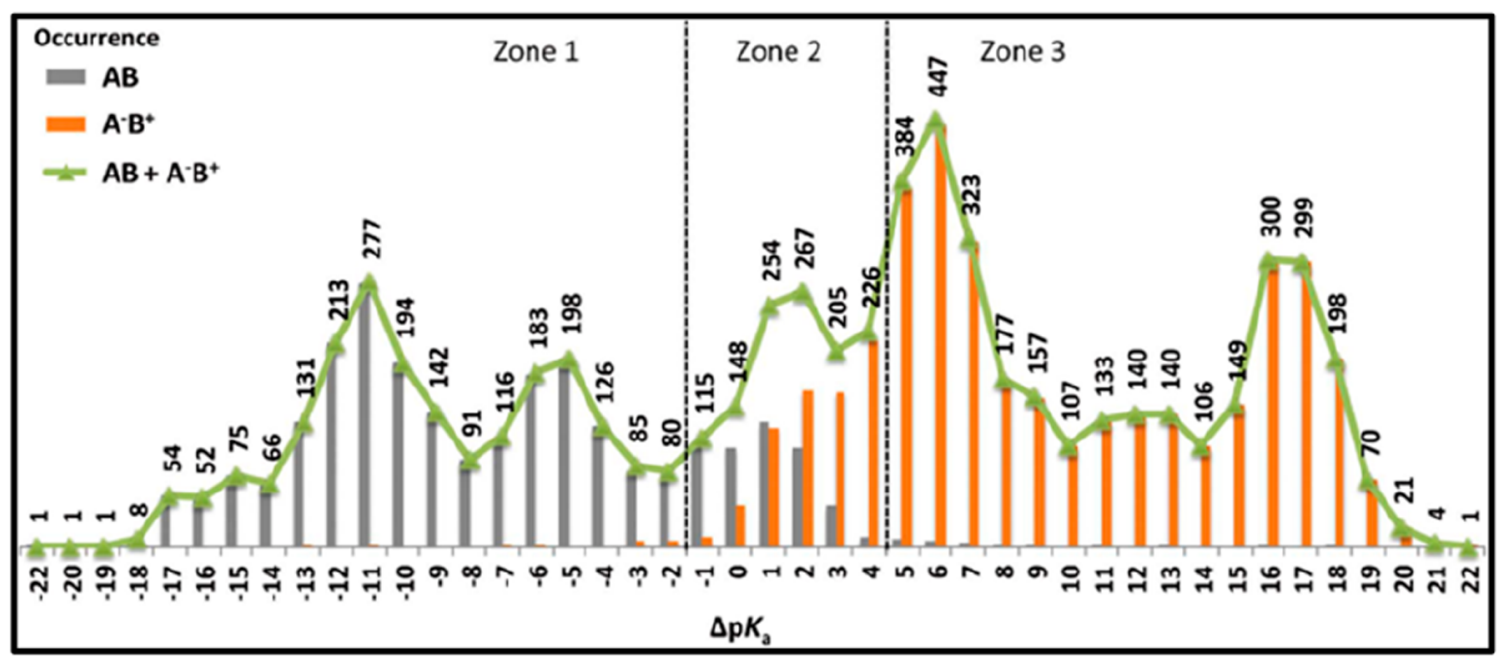

Figure 4. Occurrence of $\mathrm{AB}$ (gray) and $\mathrm{A}^{-} \mathrm{B}^{+}$(orange) as a function of the calculated $\Delta \mathrm{p} K_{\mathrm{a}}, \mathrm{AB}$ stands for acid base. ${ }^{38}$ Reprinted with permission from ref 38 .

A
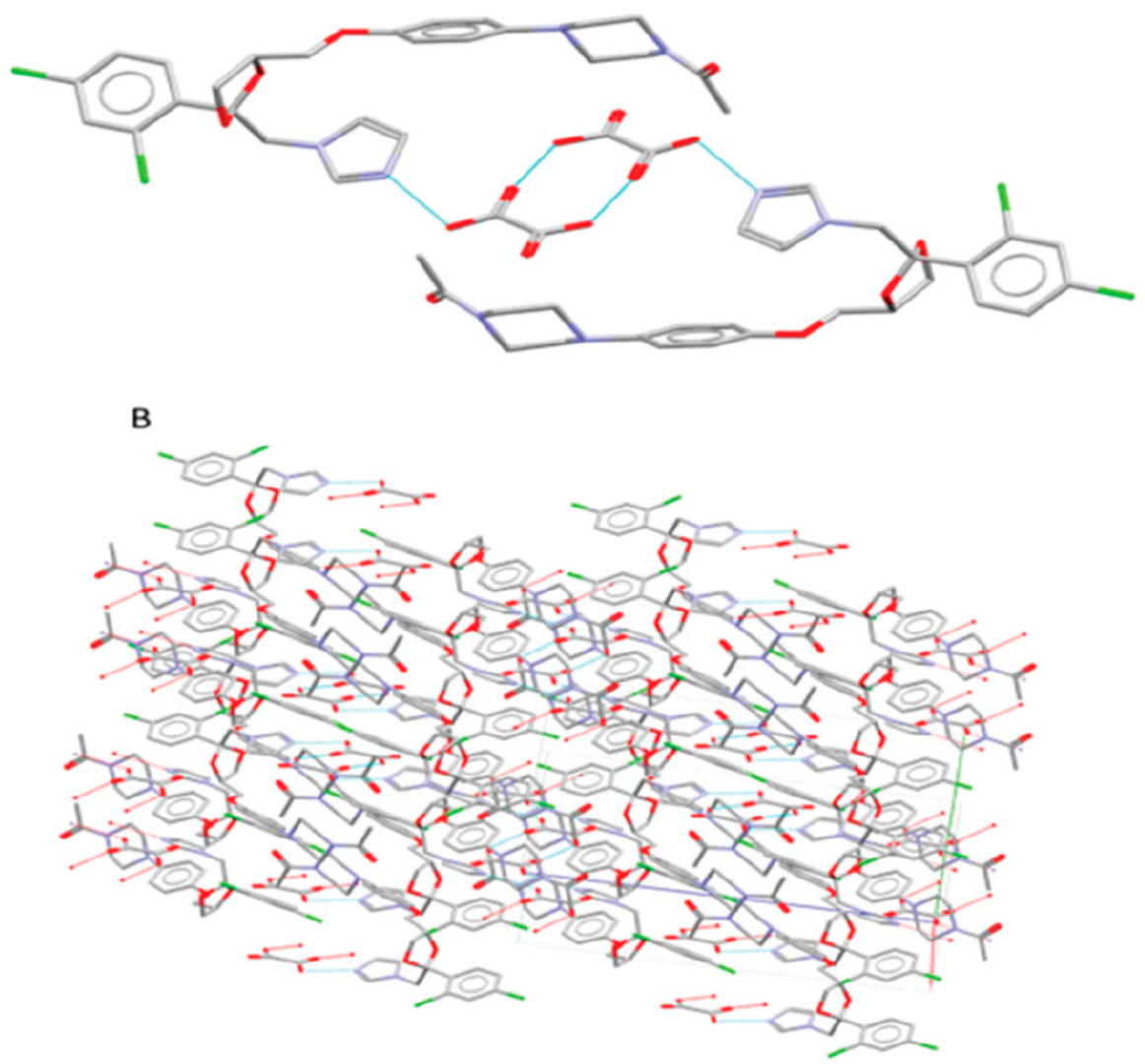

Figure 5. (A) Hydrogen bonds between oxalic acid (OA) dimers and imidazole ring of the ketoconazole (KTZ) moiety, (B) crystal packing projections for KTZ-OA salt (hydrogen bond). Other hydrogen and van der Waals bonds have been omitted for clarity.

301 highly competitive environment. High throughput experimen302 tal salt screening became an integral part of the preformulating 303 stages of drug development to narrow down the potential salt 304 forming candidates. The selected salt candidate may then be 305 promoted to the next stage of development such as scale up 306 (Figure 7). ${ }^{41,42}$ On the contrary, it is evident that, while high 307 throughput screening on the basis of different criteria such as 308 the difference of $\mathrm{p} K_{\mathrm{a}}$ values provide advantages, it also suffers from the issue that many salt forms can be overlooked by the 309 fixed protocols used. ${ }^{4-43}$

\section{METHODOLOGIES OF SALT PREPARATION}

Various techniques are used for the successful synthesis of 311 salts, among which some are considered advantageous. 312 Commonly applied techniques include solvent evaporation, 313 solution crystallization, neat grinding, liquid-assisted grinding, 314 slurrying, comelting, and vapor digestion. Other approaches 315 


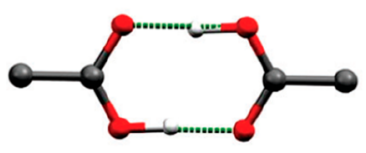

(a)

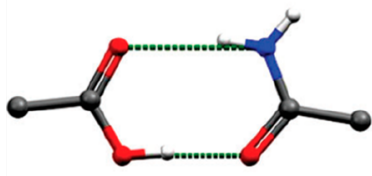

(c)

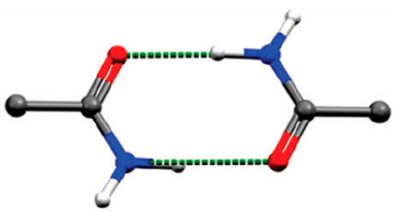

(b)

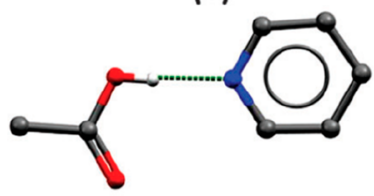

(d)
Figure 6. Common supramolecular synthons formed via hydrogen bonding, (a) carboxylic acid homosynthon exists as a dimer (b) amide homosynthon exists as dimer; supramolecular heterosynthons (c) carboxylic acid-amide heterosynthon (d) carboxylic acid-pyridine heterosynthon. ${ }^{12}$

316 include sonication, sublimation, vapor digestion, and use of 317 supercritical carbon dioxide. ${ }^{7}$ Regarding traditional manufac318 turing methods of salts, solvent addition is required to facilitate 319 the process. ${ }^{20}$ Though solvents have been viewed as necessary 320 catalysts for salt formation, their use is accompanied by a range 321 of issues such as solvate formation, greenhouse gas emissions, 322 and wastage. ${ }^{12}$ Solvate formation is an undesirable byproduct in salt processing and potentially can cause uncontrollable 323 changes to the physicochemical properties of the product 324 reacting with the bulk constituents, leading to incomplete 325 transformations and low purity batches and the creation of 326 more industrial waste. ${ }^{44,45}$ Furthermore, these require the 327 implementation of extra waste disposal systems which can raise 328 the risk of environmental hazards, while more volatile solvents 329 can impose increased health and safety considerations. ${ }^{46}$ These 330 issues highlight the need to develop solvent-free processes for 331 pharmaceutical manufacture. There are currently very few 332 solvent-free methods being used for pharmaceutical salt 333 preparation, such as mechanochemical neat grinding and 334 extrusion. ${ }^{40}$ Nevertheless, solvent processing techniques are 335 frequently used due to their ease for salt formation and scale- 336 up, the simplicity of configuration (e.g., equipment), and the 337 possibility to couple with process analytical tools (e.g., NIR, 338 Raman probes). Another advantage of solvent crystallization 339 techniques is that are usually accompanied by phase diagrams 340 and that are used to identify the salt formation mechanisms. 341

3.1. Solution Crystallization. Solution crystallization is 342 the most common method used for the formation of single salt 343 crystals after dissolution of specific amounts of API and salt 344 former in a suitable solvent. In slow crystallization, the 345 resulting solution is left undisturbed to form the single crystals 346 within a time frame, the duration of which depends on the 347 materials used (Figure 8)..$^{2,33}$ In other cases such as crystal $348 \mathrm{f} 8$

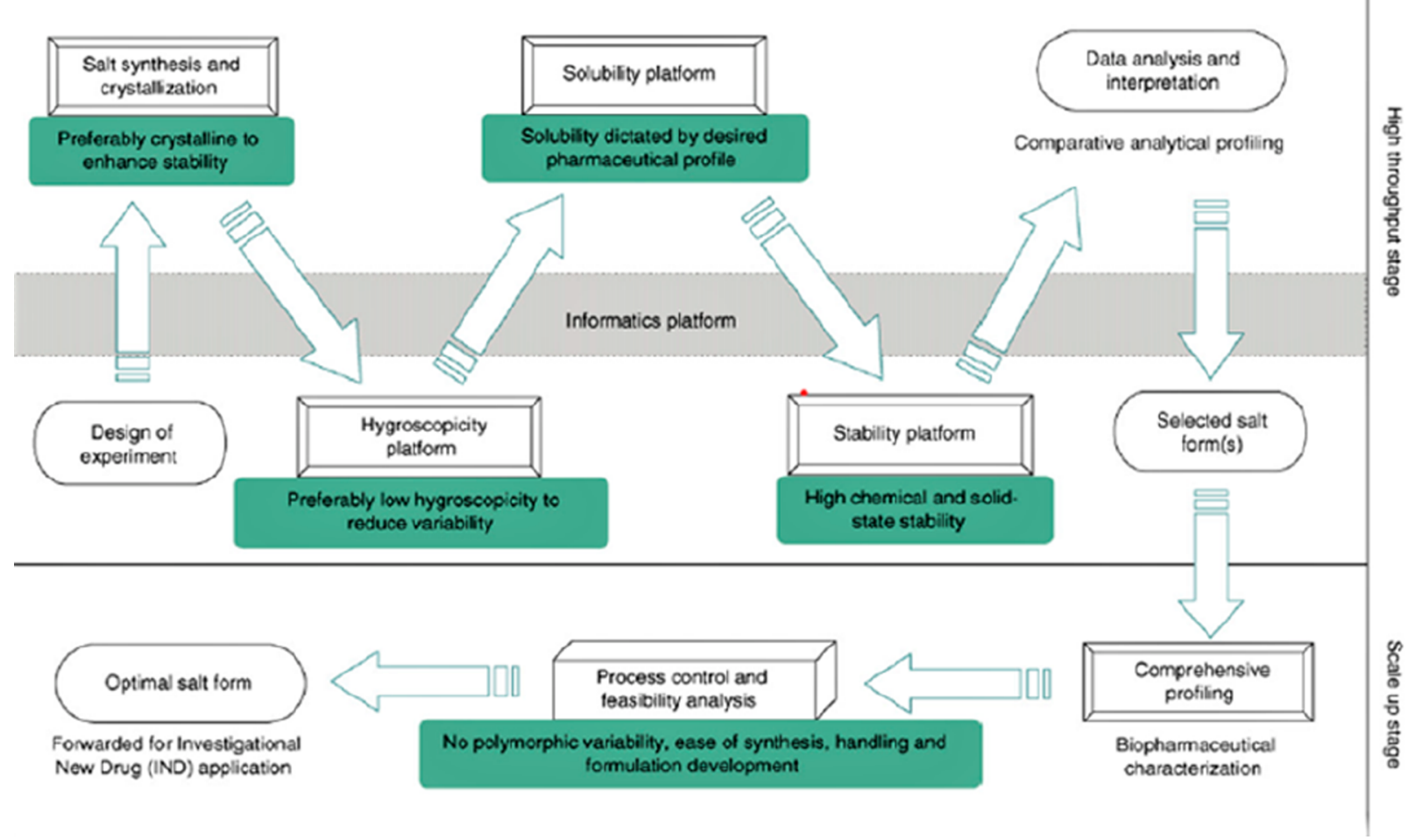

Figure 7. Stages of high-throughput salt selection showing an interface with the scale-up stage of salt screening. Each high-throughput stage is interlinked through the informatics platform. Stages depicted with double lined box indicate essential criteria, and the cuboidal box shows desirable criteria of salt selection, with the preferable parameters depicted in the underlying green shaded area. The informatics platform generates experimental design for crystallization, hygroscopicity, solubility, and stability platforms, and evaluates the analytical profile generated, to shortlist the potential salt(s). The initial "salt synthesis and crystallization" station includes a reaction platform for salt and counterion reaction, a crystallization platform for solvent recrystallization, and a solid form screening platform for initial solid form screening using X-ray diffraction, Raman, thermal, and chromatographic methods. Salt candidate(s) pass through the various stages of high-throughput salt selection (in the direction of the arrows indicated) to scale-up the stage for extensive biopharmaceutical characterization, proceeded by an assessment of desirable criteria to finalize the optimal salt form. ${ }^{41}$ Reprinted with permission from ref 41 . Copyright 2007 Elsevier. 


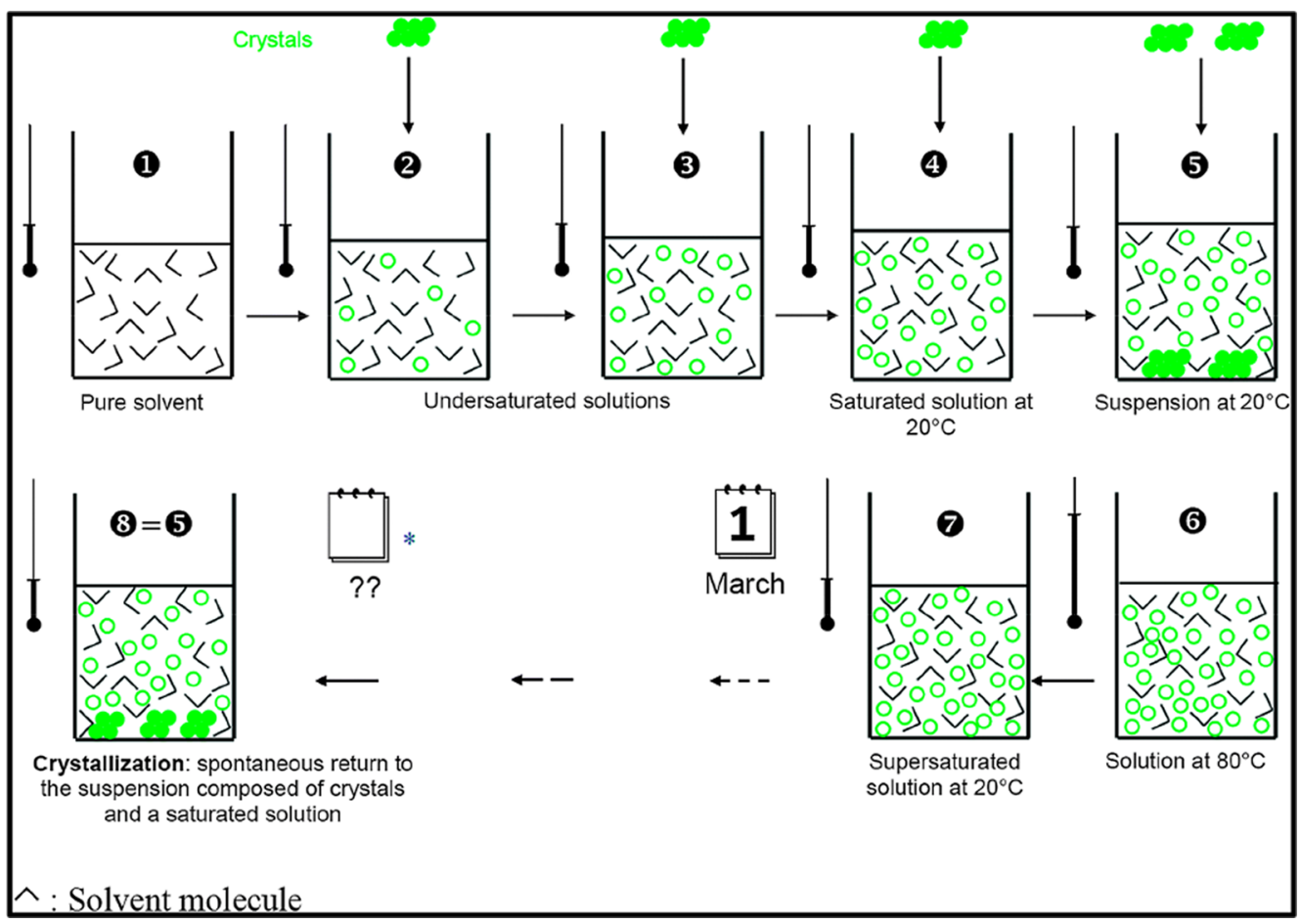

Figure 8. Cartoon illustrating an isothermal (e.g., $20{ }^{\circ} \mathrm{C}$ ) dissolution process up to saturation of the solution (from (1) to (4)), the formation of a suspension $\left(\right.$ at $20^{\circ} \mathrm{C}$ ) point 6 , the complete dissolution by heating: point $(6)$ (e.g., $40{ }^{\circ} \mathrm{C}$ ), the creation of a supersaturated solution after the return at $20^{\circ} \mathrm{C}$ (point (7) out of equilibrium). Point (8) illustrates the return to equilibrium; i.e., the concentrations of the solution in (5) and in (8) are identical. (Solvent molecules are symbolized as ${ }^{\wedge}$, and amounts of crystals of a pure component are symbolized as $\left.\mathbf{0}\right)$. Reprinted with permission from ref 33. Copyright 2014 Royal Society of Chemistry.

349 seeding, rapid precipitation, solvent evaporation heat, or 350 solvent is applied to swift the process.

351 Romanuk et al., 2009, reported the formation of saccharin 352 (SAC) salts of fluoroquinolones (FQ), norfloxacin, ciproflox353 acin (CIP), ofloxacin, and enrofloxacin to improve the low 354 solubility and bitter taste. ${ }^{48}$ Appropriate quantities of APIs and 355 saccharin (molar stoichiometric ratio 1:1) were dissolved in 356 water, and FQ-SAC salts were obtained.

357 Later, in 2010, they reported the formation of CIP358 saccharinate polymorph II and found a new form along with 359 the previously reported salts, where both forms were stable and 360 pure. Similar to FQ-SAC, appropriate quantities of CIP and 361 SAC were dissolved in hot water and were allowed to slowly 362 cool down in the dark to obtain single crystals after 2-3 days 363 (Figure 9). ${ }^{47}$

364 Chrzanowski and Ahmed, 2016, reported the formation of 365 linogliride salts to obtain extended drug release, wherein seven 366 acids were selected to attempt salt formation, but only four 367 named pamoic, $p$-hydroxybenzoic, 3-hydroxy-2-naphthoic and 368 1-napysylic acids were capable of successfully forming the salt. $369 \mathrm{pH}$ solubility profiles of the newly formed salts were 370 compared over the long $\mathrm{pH}$ range of $1.43-8.3$, against the free 371 base and the fast release linigloride fumarate salt. All the above372 mentioned salts were prepared by solution crystallization as 373 well as via the precipitation and vacuum filtration methods. 374 Interestingly, all of the multicomponent systems of linigloride 375 showed a slow dissolution rate compared to the fumarate salt, 376 which is used for immediate drug release. Three salts, except $p$ 377 hydroxybenzoate, were suggested as the potential candidate for 378 the extended release dosage forms. ${ }^{49}$

379 Surov et al., 2015, reported the formation of three 380 ciprofloxacin salts with dicarboxylic acid by solution crystal-

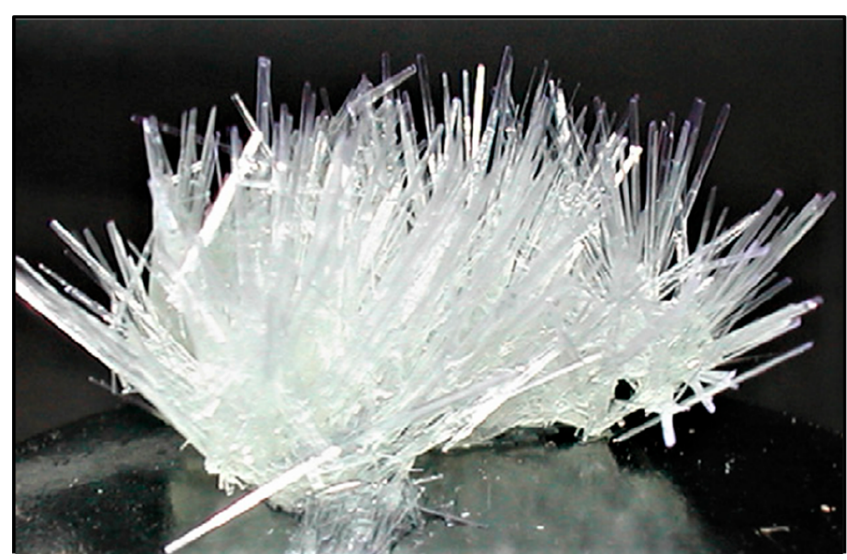

Figure 9. Single crystals of CIP-SAC II. Reprinted with permission from ref 47. Copyright 2010 Elsevier.

lization after dissolving the solids in a mixture of aqueous and 381 organic solvents. The crystalline salts of fumarate and adipate 382 contained water molecules and formed hydrates, while maleate 383 salt existed in anhydrous form. Ciprofloxacin is highly soluble 384 in acidic conditions due to the piperazine ring in the structure; 385 nonetheless, the salt showed enhanced dissolution in basic 386 media compared to the bulk CIP. ${ }^{50}$ Moreover, fumarate and 387 adipate hydrates showed higher dissolution than marketed 388 hydrochloride hydrate salt of ciprofloxacin. In continuation to 389 this work, Surov et al., 2016, reported three polymorphic forms 390 of ciprofloxacin maleate salts and one hydrate in the following 391 year, prepared by solvent drop grinding combined with 392 solution crystallization in different organic and aqueous 393 solvents and mixtures of them. They discovered that the 394 
395 form III of ciprofloxacin maleate salt was unstable due to the 396 possible kinetic instability and tendency to convert to the more 397 stable form II. It was also found that changing the processing 398 solvents had notable effects on the formation of different forms 399 of the CIP salts, even if the employed method was the same. ${ }^{44}$ 400 Similar combinatorial methods were employed by Sarmah et 401 al., 2018, where a series of olanzapine (OLZ) salts were formed 402 using pharmaceutically acceptable salt formers, i.e., malonic, 403 maleic, oxalic, succinic, glutaric, and adipic acid. Mechano404 chemical processing and solution crystallization were used for 405 the formation of different olanzapine salts, and the success of 406 this approach was established via a number of analytical 407 techniques. Most importantly, hydration stability was studied 408 at different \% RH conditions, revealing that the length of the 409 dicarboxylic acid chain in salt formation was correlated to their 410 stability. 51

411 3.2. Solvent Evaporation. Although it is difficult to find a 412 suitable solvent to dissolve poorly soluble drugs, solvent 413 evaporation is still a commonly used preparation method for 414 salts. Hence, a mixture of organic and aqueous solvents is 415 typically employed to synthesize salts using this method, 416 wherein the solvent is removed by applying heat to the 417 solution until the solvent is evaporated ${ }^{52}$ (Figure 10). Reddy et

\section{Evaporative Crystallization}

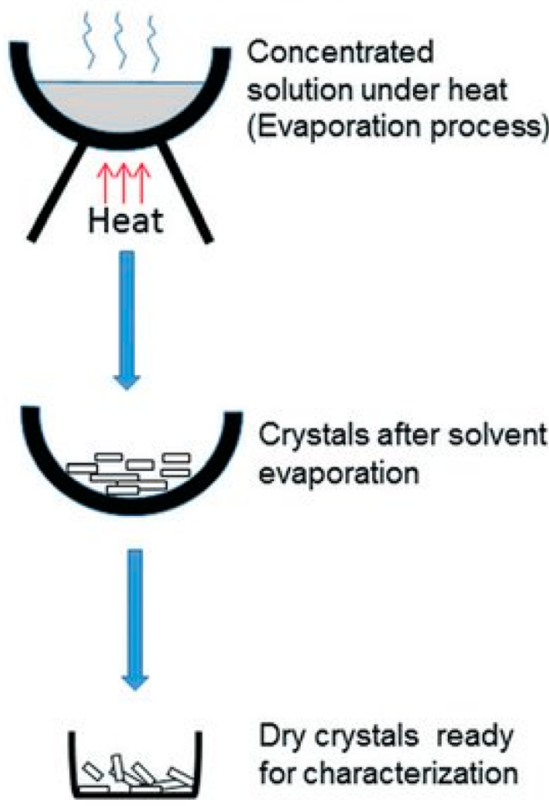

Figure 10. Traditional crystallization techniques: single droplet crystallization and evaporative crystallization. Reprinted with permission from ref 52. Copyright 2016 Royal Society of Chemistry.

418 al., 2011, reported the formation of six different forms of 419 norfloxacin (NFX) and CIP salt with five different carboxylic 420 acid salt formers. The preparation method included slow 421 evaporation of the solution in aqueous and organic solvents 422 and mixtures. NFX formed hydrates with all three carboxylic 423 acids which had a higher aqueous solubility than anhydrous 424 forms. CIP formed one anhydrous and other two hydrate salt 425 forms with enhanced properties in comparison to the bulk 426 API. $^{53}$

427 Similarly, Hiendrawan et al., 2017, prepared salts of the 428 antihypertensive drug carvedilol, with the four different GRAS 429 listed salt formers oxalic, fumaric, benzoic, and mandelic acid, using the solvent evaporation method. Several different organic 430 solvents and water, either separately or in combination, were 431 used to enable salt formation between the API and the salt 432 formers. Salts prepared using this approach were endowed with 433 a higher aqueous solubility compared to the API itself. ${ }_{434}^{54}$ Moreover, salts prepared with mandelic acid led to the 435 formation of two polymorphs where the form I was found to 436 be more stable than the other. Solvent evaporation in 437 combination with grinding has also been commonly used in 438 salt preparation. For example, Fulias et al., 2015, reported the 439 formation of a ketoprofen (KTP) salt with the amino acid 440 cysteine (CYS).

441

A physical mixture of the drug and amino acid was 442 homogeneously blended in an agate mortar for a predeter- 443 mined time, prior to making the respective solution that was 444 subjected to slow solvent evaporation to obtain the salt. ${ }^{55} 445$ Similar studies on salt preparation using a combination of KTP 446 and LYC were also reported by other researchers Panerai et al., 447 $2012^{56}$ and Stigliani et al., 2013. ${ }^{57}$ Along the same lines, 448 multicomponent solid forms of ethambutol (ETH) were 449 reported by Diniz et al., 2017, using four different 450 pharmaceutically acceptable salt formers (oxalic acid, maleic 451 acid, terephthalic acid, and trichloroacetic acid) to avoid 452 rifampicin-induced degradation during combination therapy 453 for the treatment of tuberculosis. The salts reported in this 454 study were prepared by solvent evaporation except for the 455 ETH-oxalate, which was formed by mechanochemical grinding 456 process. The developed salts had higher thermal stability than 457 the free base without the presence of any phase transition. 458 ETH-oxalate salts were observed to be non-hygroscopic, 459 whereas the other three salts retained the hygroscopic nature 460 of the free base. ${ }^{58}$

Recently, Cvetkovski et al., 2017, reported the formation of 462 two new pharmaceutical salts of pyridoxine (PYR), prepared 463 with syringic acid and ferulic acid via slow solvent evaporation, 464 after dissolving the drug and salt formers in individual solvents 465 or mixtures ( $1: 1$ stoichiometric ratio). Hirshfeld surface 466 analysis was used to explore the intermolecular interactions 467 between the API and the salt former and indicated the 468 robustness of the pyridine/carboxylic acid as supramolecular 469 synthons. $^{59}$ Ainurofiq et al., 2018, described the first 470 multicomponent crystal formation of desloratadine (an 471 antihistamine drug) with benzoic acid, where both compo- 472 nents were first dissolved in methanol, and the resulting 473 solution was evaporated at $50{ }^{\circ} \mathrm{C}$ using a rotavapor. The 474 obtained salt was characterized by various analytical techniques 475 to confirm the salt formation, and successful proton transfer 476 between the API and salt former was reported. This work also 477 included comparison with other salt formation methods 478 including neat grinding, liquid assisted grinding, and slurry 479 conversion, but successful salt formation occurred only with 480 solvent evaporation. The resulting salt exhibited enhanced 481 tabletabilty and plasticity profiles compared to the parent 482 compound, while showing improved solubility profiles in water 483 and acidic media. ${ }^{60}$

484

Solvent evaporation has also been used in combination with 485 other methods for the successful preparation of salts. Wang et 486 al., 2017, reported the formation of four different salts of 487 diphenhydramine (DPH), a first-generation H-receptor 488 antagonist, using four different salt formers: hydrochloride 489 acid (HCL), citric acid, saccharin (SAC) and acesulfumaric 490 acid (ACS). The crystalline salts of DPH-SAC and DPH-ACS 491 were prepared through the anion exchange reaction between 492 
493 DPH-HCL with Na-SAC and K-ACS, respectively. On the 494 other hand, DPH-HCL and DPH-citrate single crystals were 495 obtained by slow evaporation of a solution prepared by 496 dissolving the solids in a suitable solvent. The correlation 497 between energy framework and crystal structures were studied 498 to find the optimal mechanical properties and tabletability of 499 the prepared salt crystals. This study provided insights and 500 enabled the prediction of the tableting performance of 501 crystalline products, based on crystal structures and mechanical 502 properties. $^{61}$

503 3.3. Slurry Conversion. The slurry method, another 504 widely employed technique for the development of salts, 505 involves the preparation of a suspension by adding a small 506 amount of solvent to the physical mixture of API and salt 507 former. Hiendrawan et al., 2015, used this method to obtain 508 salts of antifungal agents, namely, ketoconazole with the GRAS 509 listed salt former, oxalic acid. Studies performed at accelerated 510 stability conditions of $40{ }^{\circ} \mathrm{C} / 75 \% \mathrm{RH}$ over the period of 1 511 month confirmed no changes to the prepared multicomponent 512 system. Also, an in vitro activity assay showed that the prepared 513 salt demonstrated equally effective antifungal action when 514 compared to the bulk ketoconazole. ${ }^{62}$ Derdour et al., 2017, 515 reported the development of a reactive slurry crystallization 516 method for salt formation to tackle issues pertaining to 517 scalability, low yield, and undesirable API powder properties 518 associated with a potent oncology drug available in industry. 519 The newly introduced slurry crystallization process was 520 developed based on the solubility behavior of both the base 521 and the salt, utilizing the base as a seed in the process, to 522 achieve supersaturation. The parent crystalline solvate was 523 crystallized first, and then the nonsolvated crystalline salt was 524 prepared from a slurry which contained the crystal of solvate. A 525 significant yield of around $90 \%$ with narrow particle size was 526 achieved using this process. This work also assessed the 527 potential of the process to be upscaled, where $50 \mathrm{~g}$ of 528 crystallites was produced without any significant difference in 529 comparison to $3 \mathrm{~g}$. Although the scaled-up method was 530 essentially the same, few parameters such as mixing effects and 531 potential hold points needed to be investigated beforehand. ${ }^{63}$ 532 In a recent review, Fernandez et al., 2015, investigated three 533 salt screening methods: the in situ salt formation, the saturated 534 solution method, and the cooling-evaporation method. The 535 outcome of this study highlighted that all the aforementioned 536 carry significant advantages as well as disadvantages. It was 537 reported that the choice of the salt screening process mostly 538 depended on the physical properties of the drug substances. 539 Hence, aripiprazole and desvenlafaxine were used as the APIs 540 along with 17 pharmaceutically acceptable acids to investigate 541 the relationship between the physical properties of the drug 542 and the salt screening process. Three different salt preparation 543 methods as mentioned earlier were evaluated aiming at 544 creating guidelines on their suitability in salt formation of 545 the APIs in question. The authors concluded the saturated 546 solution method to be the ideal choice, due to its cost547 effectiveness, efficiency, and highest hit-ratio among the three 548 methods tested in this study. However, the cooling-evaporative 549 method was suggested in cases wherein the API is possible to 550 "oil out", hereby rendering high-throughput screening 551 necessary. The study also underlined difficulties in obtaining 552 salts using APIs that may be soluble in aqueous media. For the 553 screening of water-soluble APIs, the antisolvent-based 554 crystallization process was recommended to induce the production of crystalline salts by precipitation, which is further 555 discussed in the following section. ${ }^{64}$

3.4. Vapor Diffusion with Antisolvent. During the 557 crystallization process, a second liquid or solvent can be added 558 to enhance the supersaturation process, termed as antisolvent. 559 Aqueous solvents such as water along with organic solvents can 560 be used as an antisolvent in various cases. In the vapor 561 diffusion process, the solute is dissolved in a solvent in a vial 562 and kept in an outer container which is filled with an 563 antisolvent. After the outer container is closed, an equilibrium 564 condition is established between the two liquids in a closed 565 environment resulting in crystallization. An appropriate choice 566 of solvent (should moderately solubilize the solute) and 567 antisolvent (should desolubilise the solute) should be used to 568 facilitate the vapor equilibration process. ${ }^{65}$ Chadha et al., 2016, 569 reported the formation of ciprofloxacin hippurate (CP-HA) 570 salt by solvent-assisted grinding; a combination of solution 571 creeping and vapor diffusion with antisolvent was used to 572 obtain the single crystals of the salt. The slow diffusion of 573 antisolvent vapors reduced the solubility in the preferred 574 solvent, thereby facilitating the crystal formation due to 575 supersaturation followed by precipitation. Different solvent 576 combinations such as methanol-hexane, acetone-hexane, 577 dimethoxyethane-hexane, acetonitrile-tetrahydropyran, and 578 tetrahydrofuran-cyclohexane were used in the crystallization 579 process. The processes containing hexane resulted in block- 580 shaped crystals in all cases, in contradiction with others not 581 involving hexane. An appropriate volume of a saturated 582 solution of CP-HA salt was put into small test tubes, which 583 were thereafter placed in larger test tubes, containing another 584 solvent which operated as the antisolvent. The formed salt was 585 found to be stable and demonstrated an improved aqueous 586 solubility and intrinsic dissolution rate, in comparison to the 587 bulk ciprofloxacin. ${ }^{1}$

588

3.5. Freeze-Drying Method. Freeze-drying is the removal 589 of ice or other frozen solvents from a sample through 590 sublimation, whereby bound water molecules are extracted 591 from the system through the desorption process. Elshaer et al., 592 2013, reported the preparation of a ciprofloxacin (CIP) salt 593 with two amino acids, L-glutamic and L-aspartic, from the 594 aqueous solution of the drug and salt-former that was filtered 595 and freeze-dried for $42 \mathrm{~h}$. The authors also attempted salt 596 formation using L-lysine, L-arginine, and L-histidine, without 597 any success. The role of inter- and intramolecular interactions 598 between CIP and amino acids in salt formation was studied 599 using molecular dynamic simulation, to justify the inability of 600 cationic amino acids to induce CIP salt formation. It was 601 concluded by experimental and theoretical investigation that 602 both ionic and hydrophobic interactions are essential for salt 603 formation. More explicitly, it was revealed that the ionic 604 interaction and/or hydrophilic interactions between CIP and 605 amino acids molecules should be greater than hydrophobic 606 interactions between CIP molecules. Furthermore, the 607 successfully formed glutamate and aspartate salt of CIP was 608 found to exhibit a higher dissolution rate compared to bulk 609 CIP. ${ }^{66}$

3.6. Supercritical Fluid Processing. The use of super- 611 critical fluid (SCF) in pharmaceutical product formation and 612 processing has gained enormous attention in recent years in 613 the fields of particle engineering, as well as for the development 614 of drug delivery systems. ${ }^{67,68}$ The ability of SCF to act as 615 solvent and antisolvent can be utilized effectively in the salt 616 formation of pharmaceutical actives. The SCF has been 617 
Mechanochemical Devices

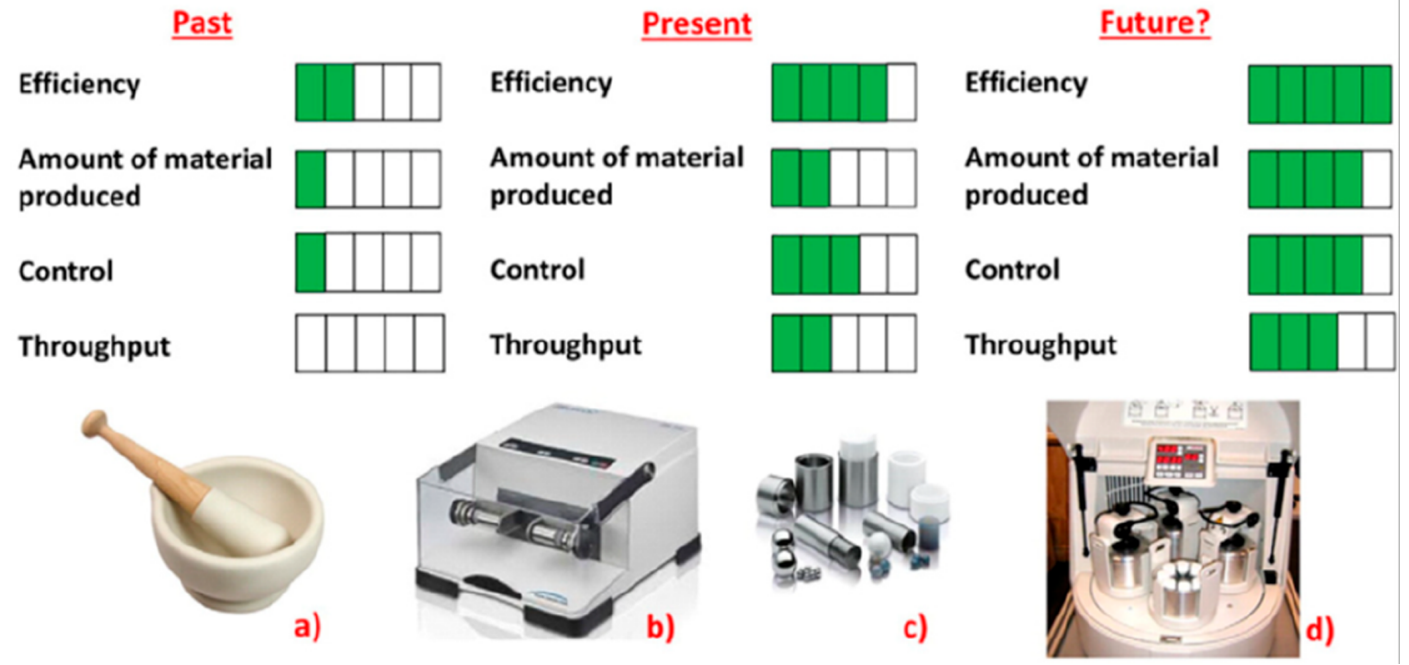

Figure 11. Top: summary of the main characteristics of past, present and possible future mechanochemical devices. Bottom: pictures of (a) mortar and pestle, (b) a modern vibrational mill with (c) a set of jars and grinding media having different volumes and composition (for more details visit www.Retsch.com) and (d) a multisampling planetary mill (for more details, visit www.automaxionltd.com).

618 commonly employed as a medium in cocrystallization, ${ }^{69,70}$ and 619 yet studies on salt formation via SCF processing are rare in the 620 literature. However, similar fundamental principles as to 621 cocrystallization can also be effectually used in SCFs-aided 622 salt formation. For example, in situ diastereomer salt formation 623 was reported by Bansaghi et al., 2012. The study attempted the 624 salt formation between racemic ibuprofen and $(R)-(1)$ 625 phenylethylamine, wherein supercritical fluid extraction from 626 the process was implemented, in order to separate the 627 unreacted enantiomers from the formed salts. The effects of 628 pressure, temperature, and reaction time were studied in detail. 629 It was discovered that when the pressure was increased, the 630 reaction rate and the resolution efficiency at equilibrium also 631 increased, while a rise in temperature resulted in the 632 improvement of the reaction rate and optical purity of 633 ibuprofen in the carbon dioxide phase. ${ }^{71}$

634 3.7. Spray Drying Processing. Spray drying has been 635 employed successfully in the formation of pharmaceutical 636 products to produce pharmaceutical dry powders, granules, 637 microspheres, coatings, amorphous formulation, cocrystals, 638 etc. $^{72}$ It is a commonly used technique in industry due to its 639 processing simplicity and cost-efficiency. During the spray 640 drying process, a liquid solution, suspension, or emulsion of 641 the compound is atomized into fine liquid droplets, which are 642 then dried by hot air maintained in the drying chamber. ${ }^{73,74}$ 643 Jensen et al., 2016, prepared coamorphous drug-amino acid 644 salts using spray drying of indomethacin and three amino acids, 645 namely, arginine, histidine, and lysine, which were previously 646 prepared by vibrational ball milling. The coamorphous form of 647 indomethacin-arginine showed improved dissolution behavior 648 in simulated intestinal fluid compared to the crystalline form of 649 the drug, which was not the case for other drug-amino acid 650 pairs. This was owed to indomethacin recrystallization during 651 dissolution, an event that affected the dissolution behavior in 652 the case of indomethacin-lysine and indomethacin-histidine 653 pairs. $^{74}$

654 Chitosan $(\mathrm{CH})$ is generally regarded as safe (GRAS) 655 excipient and drug carrier and forms salts with organic and 656 inorganic acids. Cervera et al., 2011, reported the formation of chitosan salts with three different organic acids, lactic acid, 657 citric acid, and acetic acid, by the spray drying process, after 658 the development of the aqueous solutions of chitosan-organic 659 acid mixtures. The effects of spray drying on chitosan-acid salts 660 were studied by different analytic methods, which revealed that 661 the prepared salts were amorphous. ${ }^{75}$

662

3.8. Mechanochemical Grinding. Mechanochemical 663 grinding has gained popularity as part of the screening process 664 for the development of different multicomponent pharmaceut- 665 ical products. $^{76,77}$ Previously, grinding was performed using 666 mortar and pestle, while at the present time, different highly 667 efficient devices are being used for the purpose (Figure $668 \mathrm{f} 11$ 11). ${ }^{76-78}$ In the future, the efficiency of the instrument and the $669 \mathrm{fll}$ amount of output can be possibly increased using advanced 670 technology. Neat grinding is currently widely used, as it omits 671 the use of solvents and is cost-effective. ${ }^{79}$ In view of several 672 unfruitful attempts to form salts by neat grinding, a small 673 amount of solvent was introduced during grinding, with the 674 aim to synthesize salts by a process known as solvent drop 675 grinding or liquid assisted grinding. ${ }^{79}$ The reduced cost and 676 environmentally friendly nature of this method make it 677 attractive among researchers.

Despite its popularity for multicomponent synthesis due to 679 not involving solvents, grinding suffers from a number of 680 limitations. For instance, the final product occurring from 681 grinding is usually a microcrystalline powder, and single 682 crystals are hard to obtain via this process. Mechanical energy 683 generated during the process can intensify crystalline disorder, 684 whereby products have a lower degree of crystallinity 685 compared to the solution methods. ${ }^{78}$ Furthermore, scale-up 686 using mechanochemical techniques is also troublesome and 687 often unfeasible. The choice of solvent for cogrinding is a 688 critical factor, as the solvent, which behaves as a catalyst, 689 should dissolve at least some of the original components. 690

In the cases of cocrystal formation, grinding has been 691 extensively used. ${ }^{80,81}$ Trask et al., 2006, used neat grinding and 692 solvent drop grinding as a screening method for crystalline salt 693 preparation. Two structurally similar weak nitrogen bases, 694 trimethoprim and pyrimethamine, were employed as model 695 
696 drugs along with seven well-known, pharmaceutically accept697 able acids to form salts. ${ }^{79}$

698 The efficiency of both types of the grinding method was 699 explored, revealing that neat grinding provided about $40 \%$ 700 screening efficiency, whereas a remarkable $100 \%$ was achieved 701 through the solvent drop grinding method. ${ }^{79}$ Hence, neat 702 grinding, albeit having been associated with several advantages, 703 can be an inefficient method in cases such as the one discussed. 704 Ledeti et al., 2016, reported the multicomponent formation of 705 desipramine, an antidepressant, with three pharmaceutically 706 acceptable dicarboxylic acids: glutaric, malonic, and succinic 707 acid. As tricyclic antidepressant materials have low water 708 solubility, improvements were necessary to enhance their 709 pharmacological properties. The API and salt formers were 710 mixed in an agate mortar and pestle with the addition of a few 711 drops of organic solvent. The mixing procedure was repeated 712 for each API-acid pair, and the resulting samples were dried in 713 an oven to obtain salts. Various spectroscopic and diffraction 714 analyses confirmed the formation of new crystalline products 715 by identifying the proton transfer between the materials. ${ }^{82}$

716 Kasten et al., 2017, reported the formation of crystalline and 717 coamorphous salts of indomethacin with lysine using 718 mechanochemical methods. Dry ball milling or neat grinding 719 was used to form the coamorphous salt. On the other hand, 720 liquid assisted grinding (LAG) was applied to develop the 721 crystalline form, using very small amounts of ultrapure water as 722 solvent and drying the resulting sample in a desiccator. This 723 study claimed to present the first direct comparison between 724 the crystalline and coamorphous forms of indomethacin salts, 725 highlighting the significance of the salt physical forms with 726 respect to stability and solubility. The coamorphous form of 727 the salt showed better physical stability and improved 728 dissolution rate compared to the crystalline form. ${ }^{83}$ Recently, 729 Bolla et al., 2018, reported the development of novel 730 pharmaceutical salts of an antihelmintic drug, albendazole, 731 formed with different carboxylic acids and other salt forming 732 agents. Different stoichiometric ratios of API and salt former 733 were ground together, with the addition of a few drops of 734 solvent. The resulting ground mixtures were solubilized in a 735 suitable solvent for crystallization. The resulting crystallized 736 solid salts forms were analyzed, and salt formation was 737 confirmed by single crystal diffraction and other analytic 738 techniques. $^{84}$

739 The mechanochemical grinding process has also been used 740 along with the aforementioned solvent evaporation technique. 741 Braga et al, 2013, described the formation of lidocaine salts 742 with four different dicarboxylic acids, namely, oxalic, malonic, 743 succinic, and fumaric acid, by evaporation and mechanochem744 ical grinding. All the formed salts showed enhanced thermal 745 stability compared to the free base or chloride salt of lidocaine. 746 Additionally, the dissolution rate of the formed salts was higher 747 compared to the free base but lower compared to chloride 748 salt. $^{85}$ Mechanochemical grinding also enables the formation of 749 drug-drug salts such as ciprofloxacin fumarate/adipate 750 hydrated and ciprofloxacin, with diflunisal and indoprofen, as 751 reported by Surov et al., $2015^{44}$ and Bag et al., 2014. ${ }^{86}$ To 752 achieve this, three different methods were investigated: neat 753 grinding, solvent drop grinding, and fast evaporation. The neat 754 grinding method was found to be unsuccessful, and new salts 755 were formed only through the other two methods. The 756 efficiency of the fast evaporation technique as a screening 757 method was also discussed. Single crystals of the forenamed 758 drug-drug salt were formed by the solution crystallization method. ${ }^{86}$ Zhang et al., 2016, used solvent drop grinding 759 (SDG) along with solvent evaporation as a salt screening 760 process, for the combination of ciprofloxacin along with three 761 different salt formers: fumaric, citric, and maleic acid. The 762 solubilities of all salts formed showed marked improvement 763 compared to bulk ciprofloxacin and fumarate salt (molar 764 stoichiometric ratio 1:1) and were 50-fold more soluble. ${ }^{18} 765$

3.9. Extrusion Processes and Continuous Manufac- 766 turing. Twin screw extrusion (TSE) is an emerging processing 767 technology for different types of pharmaceutical product 768 formulation. ${ }^{26}$ During the process, the materials are fed 769 through a feeder into the extruder, in certain feeding rates 770 and then extruded applying a predetermined optimum thermal 771 profile, screw speed, and screw configuration (Figure 12). $\quad 772 \mathrm{f12}$

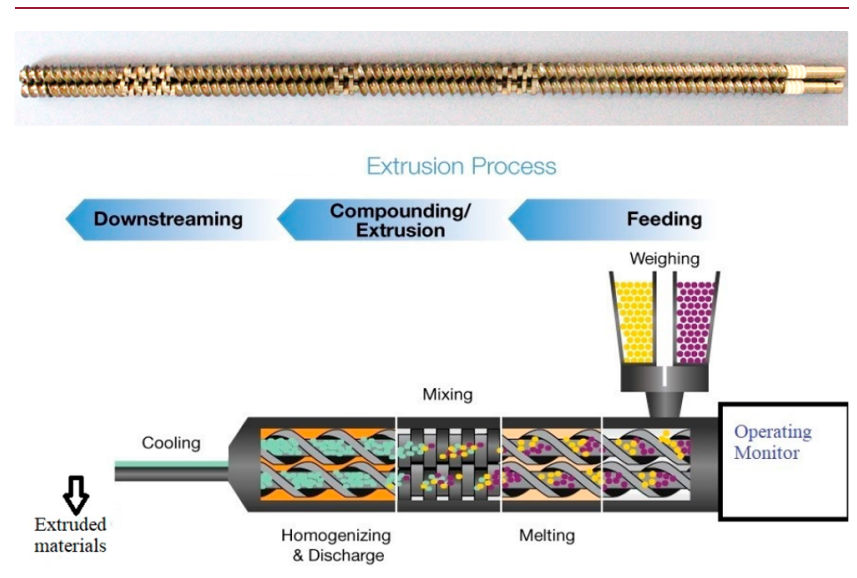

Figure 12. Representation of a complete extrusion system and screw used in extruder.

A significant amount of research work on TSE recently 773 involves cocrystal formation, ${ }^{87,88}$ while salt formation has not 774 yet been fully explored. TSE has gained abundant attraction as 775 a salt formation technique since it is similar to cocrystallization. 776 For example, Lee et al., 2017, reported the continuous 777 preparation of haloperidol-maleic acid salt by TSE. ${ }^{89}$ This 778 was the first reported continuous salt preparation method by 779 extrusion.

780

The effect of operating temperature and screw configuration 781 on salt formation were investigated. It was found that the 782 temperature had a significant effect on crystallinity, with salts 783 produced at higher temperatures being less crystalline than the 784 ones at lower temperatures.

785

With regard to screw configuration, two different config- 786 urations ( $\mathrm{A}$ and $\mathrm{B}$ ) were used, where six mixing zones screws 787 were used in configuration $\mathrm{A}$, and only three mixing zones 788 screws were used in configuration B. The conversion to salts 789 was directly related to the degree of mixing and shear intensity 790 applied, and hence screw configuration B resulted in low 791 conversion, as confirmed by broad peaks and low peak 792 intensities in powder X-ray diffraction (PXRD) analyses of the 793 formed salts. The effect of the screw configuration is a very 794 well-known phenomenon and has also been previously 795 mentioned during the cocrystal preparation via TSE 796 methods. $^{90}$

The TSE results were also compared with salts prepared by 798 various other methods such as solution crystallization, liquid 799 assisted grinding, and heat assisted grinding, deducting that 800 highly crystalline materials with identical enthalpies of melting 801 
Table 2. Advantages and Disadvantages of Pharmaceutical Salt Preparation Technologies ${ }^{24}$

\begin{tabular}{|c|c|c|}
\hline method & advantages & disadvantages \\
\hline $\begin{array}{l}\text { Solvent mediated methods (solution crystallization, solvent evaporation, } \\
\text { slurry conversion) }\end{array}$ & $\begin{array}{l}\text { - High purity } \\
\text { - Wide range of drug-coformer pairs } \\
\text { - Accurate process control }\end{array}$ & $\begin{array}{l}\text { - Not easy to scale-up } \\
\text { - Use of organic solvent }\end{array}$ \\
\hline Antisolvent crystallization & $\begin{array}{l}\text { - High purity } \\
\text { - Wide range of drug-former pairs } \\
\text { - In-line process monitoring } \\
\text { - Accurate process control }\end{array}$ & $\begin{array}{l}\text { - Time consuming } \\
\text { - Not easy to scale-up } \\
\text { - Relative low yields }(65-80 \%)\end{array}$ \\
\hline Spray drying & $\begin{array}{l}\text { - High purity } \\
\text { - Particle engineering } \\
\text { - Easy to scale up } \\
\text { - Small footprint } \\
\text { - Fast processing } \\
\text { - Wide range of drug-former pairs }\end{array}$ & $\begin{array}{l}\text { - Use of organic solvent } \\
\text { - Low yields }(40-45 \%) \\
\text { - Limited number of studies on salt } \\
\text { formation }\end{array}$ \\
\hline Freeze-drying & $\begin{array}{l}\text { - High purity } \\
\text { - Suitable for thermolabile materials } \\
\text { - Accurate process control } \\
\text { - Relative high yields }\end{array}$ & $\begin{array}{l}\text { - Time consuming } \\
\text { - Not easy to scale-up } \\
\text { - Costly } \\
\text { - Solvent residues } \\
\text { - Limited number of studies }\end{array}$ \\
\hline Supercritical fluid processing & $\begin{array}{l}\text { - High purity } \\
\text { - Suitable for thermolabile materials. } \\
\text { - Accurate process control } \\
\text { - Use of low processing temperature }\end{array}$ & $\begin{array}{l}\text { - Time consuming } \\
\text { - Limited number of studies } \\
\text { - Solvent residues }\end{array}$ \\
\hline Mechanochemical neat grinding & $\begin{array}{l}\text { - Good purity salts } \\
\text { - Wide range of drug-coformer pairs } \\
\text { - Particle size reduction } \\
\text { - Environmentally friendly, no solvents } \\
\text { - Isolate polymorphs of same salt } \\
\text { - Use different stoichiometric ratios }\end{array}$ & $\begin{array}{l}\text { - Low yield } \\
\text { - Scale-up issues } \\
\text { - Time consuming } \\
\text { - Every time not in a reproducible } \\
\text { manner }\end{array}$ \\
\hline Liquid assisted grinding & $\begin{array}{l}\text { - High purity } \\
\text { - Wide range of drug-coformer pairs } \\
\text { - Broader range of synthesized salts and } \\
\text { cocrystals } \\
\text { - Particle size reduction } \\
\text { - Fast processing } \\
\text { - Isolate polymorphs of same cocrystals } \\
\text { - Use different stoichiometric ratios }\end{array}$ & $\begin{array}{l}\text { - Use of solvents } \\
\text { - Scale-up issues }\end{array}$ \\
\hline Extrusion & $\begin{array}{l}\text { - High purity } \\
\text { - Continuous process } \\
\text { - Easy to scale-up } \\
\text { - Small footprint } \\
\text { - Environmentally friendly, no solvents } \\
\text { - Short residence time } \\
\text { - In-line process monitoring } \\
\text { - Wide range of drug-coformer pairs }\end{array}$ & $\begin{array}{l}\text { - Only one polymorph of the same } \\
\text { cocrystal }\end{array}$ \\
\hline
\end{tabular}

802 were formed by both solution crystallization and melt 803 extrusion.

804 After the previous report, Bookwala et al., 2018, reported the 805 preparation of a crystalline salt of indomethacin and trometh806 amine using hot melt extrusion (HME). ${ }^{91}$ Samples from 807 different zones were collected, aiming at monitoring the 808 progress of salt formation, and the finished salt form was 809 compared with the salts prepared via the solvent evaporation 810 method. The salt formation was studied at various stoichio811 metric ratios of API and salt former, determining that only the 812 1:1 ratio successfully resulted in a salt. The melt enthalpy for 813 the salt prepared by the two methods suggested that the salts 814 obtained by solvent evaporation had higher conversion (99\% instead of $95 \%$ with $\mathrm{HME}$ ) and crystallinity than the salt 815 formed by extrusion.

The salt formation had a notable effect on the dissolution 817 profile of bulk materials, where $100 \%$ of the drug of the salts 818 was released within $5 \mathrm{~min}$, regardless of their method of 819 preparation. On the basis of the collected data, it was 820 concluded that HME can result in uniform mixing of the 821 materials, that helps to accomplish content uniformity. The 822 drug content of extruded materials was determined to be 823 approximately 98\%, to which the optimization of screw 824 configuration during the extrusion process had a significant 825 contribution. 
827 Recently, a ketoconazole oxalate (Figure 5) and cipro828 floxacin maleate salt were manufactured through thermome829 chanical twin-screw extrusion, reported by Mithu et al., 2019. 830 Salts prepared by extrusion were compared with the respective 831 salt produced by mechanochemical grinding, and notably, the 832 purity of the salts produced by both techniques was identical. 833 The progress of salt formation in different extrusion zones was 834 determined by analyzing the sample collected from different 835 zones. The analyses illustrated that the rate of salt formation 836 depends on the availability of the proton donor and acceptor in 837 the API-salt former mixture, along with other extrusion 838 parameters. $^{40}$

839 All the aforementioned technologies employed for the 840 synthesis of pharmaceutical salts, including their advantages 841 and disadvantages, are presented in Table 2.

\section{SALT CHARACTERIZATION TECHNIQUES}

842 Techniques such as crystallography single crystal X-ray 843 diffraction (SCXRD), powder X-ray diffraction (PXRD), 844 thermal analysis such as differential thermal analysis (DTA), 845 differential scanning calorimetry (DSC), thermogravimetric 846 analysis (TGA), and others are commonly used to analyze the 847 newly synthesized pharmaceutical salts.

848 PXRD is a fast-analytical technique, mainly used for phase 849 identification of a crystalline material, and it can provide 850 detailed information on unit cell dimensions of the solid 851 materials. The pattern detected by PXRD is unique to the 852 polymorphic form and also allows verification of whether the 853 material is crystalline/amorphous, as amorphous materials will 854 generate a featureless halo. ${ }^{92}$

855 The appearance of the peaks can provide detailed 856 information on the uniformity, where broadened peaks 857 indicate a lack of crystallinity, including the information 858 related to particle size. SCXRD is used to determine the new 859 diffraction pattern of a single crystal, in order to identify the 860 new crystalline materials. Recently, along with SCXRD, X-ray 861 photoelectron spectroscopy (XPS) was also used to identify 862 the proton transfer during the salt formation. ${ }^{93}$

863 Solid-state nuclear magnetic resonance (SSNMR) can be 864 used to identify the structure of salts, crystal packing, hydrogen 865 bond environments, and the number of independent molecules 866 in molecular complexes, although it requires an experienced 867 person to interpret the obtained data. ${ }^{94}$ Fourier transform 868 infrared spectroscopy (FTIR) and Raman spectroscopy are 869 readily available and can be used to evaluate interactions in the 870 solid state, particularly by supporting PXRD data for chemical 871 structure identification by pointing out functional groups/ 872 phases, and hydrogen bond analysis based on bond stretching 873 and bending frequencies. ${ }^{95,96}$ During the salt formation, 874 interaction occurs between the functional group of the APIs 875 and salt former, and this can be identified by studying peak 876 shift of the major functional group of the materials with the 877 help of FTIR and Raman spectroscopy analysis.

878 Thermal analysis including differential thermal analysis 879 (DTA), differential scanning calorimetry (DSC), and ther880 mogravimetric analysis (TGA) are easy to perform and are 881 readily available in most laboratories to attain information 882 regarding melting, glass transitions, crystallization, decom883 position, and solid-state transitions. ${ }^{97}$ These techniques can be 884 extremely helpful in predicting solubility and stability through 885 the analysis of the melting endotherm sharpness, which can 886 provide an indication of the purity and crystallinity of the 887 sample. Complex thermograms may also reveal polymorphism, which can be vital in the search for the most stable form. 888 Furthermore, TGA can detect the measure of the weight 889 change either at a constant temperature or as a function of the 890 changing temperature, by which hydrates and solvates can 891 generally be separated from anhydrous forms due to the nature 892 of the endotherm associated with the weight change of 893 samples. Hot stage microscopy (HSM) or thermomicroscopy 894 can provide invaluable information on the physical character- 895 ization of pharmaceutical materials in relation to temper- 896 ature. ${ }^{98}$ These microscopy techniques provide valuable visual 897 information pertaining to polymorphic transitions, thermal 898 behavior displayed by materials, and thermal inhomogeneities 899 of the sample surface (Figure 13) that are not detected by $900 \mathrm{fl} 3$

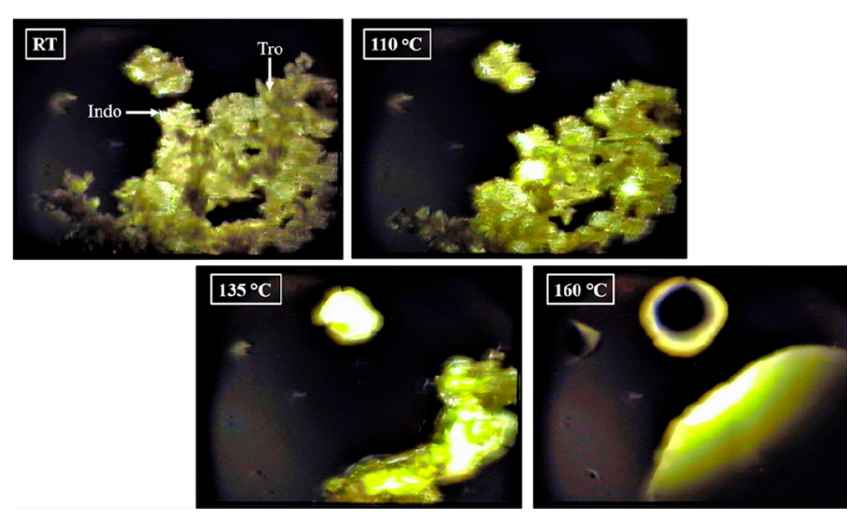

Figure 13. Hot stage polarized light microscopy of a $1: 1$ indomethacin and tromethamine physical mixture. Reprinted with permission from ref 91. Copyright 2018 Elsevier.

DSC. ${ }^{91}$ Other routine characterization methodologies based 901 on microscopy such as scanning electron microscopy (SEM) 902 are intended to examine visual attributes of the pharmaceutical 903 salts related to particle size, crystal habits, and morphology. ${ }^{40} 904$

\section{REGULATORY PERSPECTIVES}

Pharmaceutically relevant salts have been manufactured for a 905 long time, and regulatory bodies have published clear 906 corresponding guidelines. Salts are always considered as new 907 entities, and this can be advantageous compared to cocrystals, 908 from the perspective of regulatory framework and issue of 909 patents. In 2013, the FDA published a set of directives for 910 pharmaceutical cocrystals: "Cocrystals are crystalline material 911 composed of two or more molecules within the same crystal 912 lattice" (FDA guidelines, 2013). ${ }^{99}$ Recently, in 2018, the FDA 913 revised the latter, redefining cocrystals as "Crystalline materials 914 composed of two or more different molecules, one of which is 915 the API, in a defined stoichiometric ratio within the same 916 crystal lattice that are associated by non-ionic and noncovalent 917 bonds" (FDA guidelines 2018). ${ }^{15}$ According to the guidance 918 provided by the FDA, salt formation and cocrystal formation 919 can be differentiated by the $\mathrm{p} K_{\mathrm{a}}$ difference between the API 920 and the coformers. If the $\Delta \mathrm{p} K_{\mathrm{a}}$ between the API and the 921 coformer is greater or equal to 1 , there must be ionization 922 owed to proton transfer, and the process will be referred to as 923 salt formation. However, if the $\Delta \mathrm{p} K_{\mathrm{a}}$ is less than 1 , the chance 924 of proton transfer minimizes and cocrystals can be formed due 925 to a nonionic reaction. According to the FDA, cocrystals are 926 not new APIs as they were classified as drug product 927 intermediates (DPIs) in 2013. If the cocrystals are formed 928 by two or more APIs with or without a coformer, they are also 929 
930 not treated as a new API, unlike salts, but only as a fixed dose 931 combination product.

932 According to the European medicines agency (EMA), as like 933 as FDA, salts are considered as new entity, and cocrystals are 934 defined as "homogenous (single phase) crystalline structures 935 made up of two or more components in a specific 936 stoichiometric ratio where the arrangement in the crystal 937 lattice is not based on ionic bonds". ${ }^{100}$ The current regulatory 938 framework considers each new salt as a new API, even if it is 939 produced using the same drug. Hence, unlike cocrystals, salts 940 still present an interesting potential for the pharmaceutical 941 industry with regard to generating novel IPs.

\section{CONCLUSIONS}

942 Because of the lack of favorable physicochemical properties 943 that would accommodate pharmaceutical applications, APIs 944 are being modified to form multicomponent compounds to 945 achieve better clinical performance. Pharmaceutical salt 946 formation is the first choice among various approaches when 947 it comes to improving the properties of APIs. Moreover, the 948 availability of various methods to produce salts along with the 949 longevity of these systems in the pharmaceutical industry 950 makes them a confident choice when looking for an approach 951 to improve the physicochemical properties of pharmaceutical 952 actives. In this review, we discussed a wide range of methods 953 applied for the preparation of pharmaceutical salts in order to 954 improve poor physical properties of APIs. Recent advances in 955 processing technologies have led to the manufacturing of 956 scalable, high-quality pharmaceutical salts by using green 957 chemistry approaches. Although various approaches have 958 shown promising results for salt preparation, only a handful 959 of techniques are being repeatedly used, due to the ease of 960 production with appropriate specifications. From the regu961 latory perspective, pharmaceutical salts are well accepted; 962 however, there are several challenges including salt former 963 selection, physicochemical characterization, and formulation. 964 Nonetheless, different current methodologies of salt formation 965 along with newly introduced methods make salt preparation 966 more efficient and viable for the pharmaceutical industry.

$967 \square$ AUTHOR INFORMATION

968 Corresponding Author

969 Dennis Douroumis - Department of Pharmaceutical,

970 Chemical and Environmental Sciences, Faculty of Engineering

971 and Science, University of Greenwich, Chatham Maritime,

972 Kent ME4 4TB, U.K.; Centre for Innovation and Process

973 Engineering Research, U.K.; ○ orcid.org/0000-0002-3782-

974 0091; Email: D.Douroumis@gre.ac.uk

\section{Authors}

976 Md Sadeque Hossain Mithu - Department of

977 Pharmaceutical, Chemical and Environmental Sciences,

978 Faculty of Engineering and Science, University of Greenwich,

979 Chatham Maritime, Kent ME4 4TB, U.K.; (1) orcid.org/

$980 \quad$ 0000-0002-2584-3886

981 Sophia Economidou - Medway School of Pharmacy,

982 University of Kent, Chatham, Kent ME4 4TB, U.K.

983 Vivek Trivedi - Medway School of Pharmacy, University of

984 Kent, Chatham, Kent ME4 4TB, U.K.

985 Saumil Bhatt - Cubic - Tech Extrusion Ltd., Rochester, Kent 986 ME2 4LU, U.K.

987 Complete contact information is available at: 988 https://pubs.acs.org/10.1021/acs.cgd.0c01427
Notes

The authors declare no competing financial interest.

\section{ACKNOWLEDGMENTS}

991

This project has received funding from the Interreg 2 Seas 992 programme 2014-2020 cofunded by the European Regional 993 Development Fund under subsidy contract 2S01-059 IMODE 994

\section{REFERENCES}

995

(1) Chadha, R.; Singh, P.; Khullar, S.; Mandal, S. K. Ciprofloxacin 996 Hippurate Salt: Crystallization Tactics, Structural Aspects, and 997 Biopharmaceutical Performance. Cryst. Growth Des. 2016, 16, 998 4960-4967.

999

(2) Berry, D. J.; Steed, J. W. Pharmaceutical Cocrystals, Salts and 1000 Multicomponent Systems; Intermolecular Interactions and Property 1001 Based Design. Adv. Drug Delivery Rev. 2017, 117, 3-24.

1002

(3) Almeida E Sousa, L.; Reutzel-Edens, S. M.; Stephenson, G. A.; 1003 Taylor, L. S. Supersaturation Potential of Salt, Co-Crystal, and 1004 Amorphous Forms of a Model Weak Base. Cryst. Growth Des. 2016, 1005 16, 737-748.

1006

(4) Kalepu, S.; Nekkanti, V. Insoluble Drug Delivery Strategies: 1007 Review of Recent Advances and Business Prospects. Acta Pharm. Sin. 1008 B 2015, 5, 442-453.

1009

(5) Arnott, J. A.; Planey, S. L. The Influence of Lipophilicity in Drug 1010 Discovery and Design. Expert Opin. Drug Discovery 2012, 7, 863-875. 1011

(6) Taylor, D. The Pharmaceutical Industry and the Future of Drug 1012 Development. In Pharmaceuticals in the Environment; Hester, R. E., 1013 Harrison, R. M., Eds.; Royal Society of Chemistry: Cambridge, 2016; 1014 pp 1-33.

1015

(7) Vioglio, P. C.; Chierotti, M. R.; Gobetto, R. Pharmaceutical 1016 Aspects of Salt and Cocrystal Forms of APIs and Characterization 1017 Challenges. Adv. Drug Delivery Rev. 2017, 117, 86-110. 1018

(8) Elder, D. P.; Holm, R.; de Diego, H. L. Use of Pharmaceutical 1019 Salts and Cocrystals to Address the Issue of Poor Solubility. Int. J. 1020 Pharm. 2013, 453, 88-100.

1021

(9) Aitipamula, S.; Banerjee, R.; Bansal, A. K.; Biradha, K.; Cheney, 1022 M. L.; Choudhury, A. R.; Desiraju, G. R.; Dikundwar, A. G.; Dubey, 1023 R.; Duggirala, N.; Ghogale, P. P.; Ghosh, S.; Goswami, P. K.; Goud, 1024 N. R.; Jetti, R. R. K. R.; Karpinski, P.; Kaushik, P.; Kumar, D.; Kumar, 1025 V.; Moulton, B.; Mukherjee, A.; Mukherjee, G.; Myerson, A. S.; Puri, 1026 V.; Ramanan, A.; Rajamannar, T.; Reddy, C. M.; Rodriguez-Hornedo, 1027 N.; Rogers, R. D.; Row, T. N. G.; Sanphui, P.; Shan, N.; Shete, G.; 1028 Singh, A.; Sun, C. C.; Swift, J. A.; Thaimattam, R.; Thakur, T. S.; 1029 Kumar Thaper, R.; Thomas, S. P.; Tothadi, S.; Vangala, V. R.; 1030 Variankaval, N.; Vishweshwar, P.; Weyna, D. R.; Zaworotko, M. J. 1031 Polymorphs, Salts, and Cocrystals: What's in a Name? Cryst. Growth 1032 Des. 2012, 12, 2147-2152. 1033

(10) Martin, F. A.; Pop, M. M.; Borodi, G.; Filip, X.; Kacso, I. 1034 Ketoconazole Salt and Co-Crystals with Enhanced Aqueous 1035 Solubility. Cryst. Growth Des. 2013, 13, 4295-4304.

1036

(11) Kawakami, K. Modification of Physicochemical Characteristics 1037 of Active Pharmaceutical Ingredients and Application of Super- 1038 saturatable Dosage Forms for Improving Bioavailability of Poorly 1039 Absorbed Drugs. Adv. Drug Delivery Rev. 2012, 64, 480-495. 1040

(12) Duggirala, N. K.; Perry, M. L.; Almarsson, Ö.; Zaworotko, M. J. 1041 Pharmaceutical Cocrystals: Along the Path to Improved Medicines. 1042 Chem. Commun. 2016, 52, 640-655. 1043

(13) Pudipeddi, M.; Serajuddin, A. T. M. Trends in Solubility of 1044 Polymorphs. J. Pharm. Sci. 2005, 94, 929-939.

1045

(14) McNaught, A. D.; Wilkinson, A. IUPAC. Compendium of 1046 Chemical Terminology, 2nd ed.; Blackwell Scientific Publications: 1047 Oxford, 1997.

1048

(15) FDA. Guidance for Industry: Regulatory Classification of 1049 Pharmaceutical Co-Crystals Guidance for Industry, 2018.

(16) Serajuddin, A. T. M. Salt Formation to Improve Drug 1051 Solubility. Adv. Drug Delivery Rev. 2007, 59, 603-616. 1052

(17) Thakral, N. K.; Kelly, R. C. Salt Disproportionation: A Material 1053 Science Perspective. Int. J. Pharm. 2017, 520, 228-240. 
1055 (18) Zhang, G.; Zhang, L.; Yang, D.; Zhang, N.; He, L.; Du, G.; Lu, 1056 Y. Salt Screening and Characterization of Ciprofloxacin. Acta 1057 Crystallogr., Sect. B: Struct. Sci., Cryst. Eng. Mater. 2016, 72, 20-28. 1058 (19) Nie, H.; Byrn, S. R.; Zhou, Q. T. Stability of Pharmaceutical 1059 Salts in Solid Oral Dosage Forms. Drug Dev. Ind. Pharm. 2017, 43, 1060 1215-1228.

1061 (20) Wiedmann, T.; Naqwi, A. Pharmaceutical Salts: Theory, Use in 1062 Solid Dosage Forms and in Situ Preparation in an Aerosol. Asian J. 1063 Pharm. Sci. 2016, 11, 722-734.

1064 (21) Zhu, H.; Xu, J.; Varlashkin, P.; Long, S.; Kidd, C. Dehydration, 1065 Hydration Behavior, and Structural Analysis of Fenoprofen Calcium. 1066 J. Pharm. Sci. 2001, 90, 845-859.

1067 (22) Morris, K. R.; Griesser, U. J.; Eckhardt, C. J.; Stowell, J. G. 1068 Theoretical Approaches to Physical Transformations of Active 1069 Pharmaceutical Ingredients during Manufacturing Processes. Adv. 1070 Drug Delivery Rev. 2001, 48, 91-114.

1071 (23) Biswas, N. Solid Forms and Pharmacokinetics. In Pharmaceut1072 ical Salts and Co-Crystals; Wouters, J., Quéré, L., Eds.; Royal Society 1073 of Chemistry: Cambridge, 2012; pp 128-153.

1074 (24) Douroumis, D.; Ross, S. A.; Nokhodchi, A. Advanced 1075 Methodologies for Cocrystal Synthesis. Adv. Drug Delivery Rev. 1076 2017, 117, 178-195.

1077 (25) Steed, J. W. The Role of Co-Crystals in Pharmaceutical Design. 1078 Trends Pharmacol. Sci. 2013, 34, 185-193.

1079 (26) Ross, S. A.; Lamprou, D. A.; Douroumis, D. Engineering and 1080 Manufacturing of Pharmaceutical Co-Crystals: A Review of Solvent1081 Free Manufacturing Technologies. Chem. Commun. 2016, 52, 877210828786.

1083 (27) Clarke, H. D.; Arora, K. K.; Bass, H.; Kavuru, P.; Ong, T. T.; 1084 Pujari, T.; Wojtas, L.; Zaworotko, M. J. Structure-Stability Relation1085 ships in Cocrystal Hydrates: Does the Promiscuity of Water Make 1086 Crystalline Hydrates the Nemesis of Crystal Engineering? Cryst. 1087 Growth Des. 2010, 10, 2152-2167.

1088 (28) Khankari, R. K.; Grant, D. J. W. Pharmaceutical Hydrates. 1089 Thermochim. Acta 1995, 248, 61-79.

1090 (29) Bastin, R. J.; Bowker, M. J.; Slater, B. J. Salt Selection and 1091 Optimisation Procedures for Pharmaceutical New Chemical Entities. 1092 Org. Process Res. Dev. 2000, 4, 427-435.

1093 (30) Qiu, J.; Patel, A.; Stevens, J. M. High Throughput Salt 1094 Screening of Synthetic Intermediates: Effects of Solvent, Counter-Ion 1095 and Counter-Ion Solubility and Counter-Ion Solubility. Org. Process 1096 Res. Dev. 2020, 24, 1262-1270.

1097 (31) Paulekuhn, G. S.; Dressman, J. B.; Saal, C. Trends in Active 1098 Pharmaceutical Ingredient Salt Selection Based on Analysis of the 1099 Orange Book Database. J. Med. Chem. 2007, 50, 6665-6672.

1100 (32) Malamatari, M.; Ross, S. A.; Douroumis, D.; Velaga, S. P. 1101 Experimental Cocrystal Screening and Solution Based Scale-up 1102 Cocrystallization Methods. Adv. Drug Delivery Rev. 2017, 117, 1621103177.

1104 (33) Coquerel, G. Crystallization of Molecular Systems from 1105 Solution: Phase Diagrams, Supersaturation and Other Basic Concepts. 1106 Chem. Soc. Rev. 2014, 43, 2286-2300.

1107 (34) Gardner, C. R.; Walsh, C. T.; Almarsson, Ö. Drugs as 1108 Materials: Valuing Physical Form in Drug Discovery. Nat. Rev. Drug 1109 Discovery 2004, 3, 926-934.

1110 (35) Bevill, M. J.; Vlahova, P. I.; Smit, J. P. Polymorphic Cocrystals 1111 of Nutraceutical Compound $p$-Coumaric Acid with Nicotinamide: 1112 Characterization, Relative Solid-State Stability, and Conversion to 1113 Alternate Stoichiometries. Cryst. Growth Des. 2014, 14, 1438-1448. 1114 (36) Gokhale, M. Y.; Mantri, R. V. API Solid-Form Screening and 1115 Selection. In Developing Solid Oral Dosage Forms: Pharmaceutical 1116 Theory and Practice, 2nd ed.; Qiu, Y., Chen, Y., Zhang, G. G. Z., Yu, 1117 L., Mantri, R. V., Eds.; Academic Press: London, 2016; pp 85-112. 1118 (37) Hawkes, S. J. All Positive Ions Give Acid Solutions in Water. J. 1119 Chem. Educ. 1996, 73, 516-517.

1120 (38) Cruz-Cabeza, A. J. Acid-Base Crystalline Complexes and the 1121 PKa Rule. CrystEngComm 2012, 14, 6362-6365.

1122 (39) Yang, J.; Yin, L.; Gong, X.-D.; Zhang, J.-G.; Sinditskii, V. P. 1123 Origins of Salt-Formation and Co-Crystallization: A Combined
Experimental and Theoretical Study. Cryst. Growth Des. 2020, 20, 1124 5834-5842.

1125

(40) Mithu, M. S. H.; Ross, S. A.; Alexander, B. D.; Douroumis, D. 1126 Solid State Thermomechanical Engineering of High-Quality Pharma- 1127 ceutical Salts via Solvent Free Continuous Processing. Green Chem. 1128 2020, 22, 540-549.

1129

(41) Kumar, L.; Amin, A.; Bansal, A. K. An Overview of Automated 1130 Systems Relevant in Pharmaceutical Salt Screening. Drug Discovery 1131 Today 2007, 12, 1046-1053.

1132

(42) Black, S. N.; Collier, E. A.; Davey, R. J.; Roberts, R. J. Structure, 1133 Solubility, Screening, and Synthesis of Molecular Salts. J. Pharm. Sci. 1134 2007, 96, 1053-1068.

1135

(43) Nievergelt, P. P.; Babor, M.; Cejka, J.; Spingler, B. A High 1136 Throughput Screening Method for the Nano-Crystallization of Salts 1137 of Organic Cations. Chem. Sci. 2018, 9, 3716-3722.

1138

(44) Surov, A. O.; Churakov, A. V.; Perlovich, G. L. Three 1139 Polymorphic Forms of Ciprofloxacin Maleate: Formation Pathways, 1140 Crystal Structures, Calculations, and Thermodynamic Stability 1141 Aspects. Cryst. Growth Des. 2016, 16, 6556-6567. 1142

(45) Madusanka, N.; Eddleston, M. D.; Arhangelskis, M.; Jones, W. 1143 Polymorphs, Hydrates and Solvates of a Co-Crystal of Caffeine with 1144 Anthranilic Acid. Acta Crystallogr., Sect. B: Struct. Sci., Cryst. Eng. 1145 Mater. 2014, 70, 72-80.

1146

(46) Sheldon, R. A. The E Factor 25 Years on: The Rise of Green 1147 Chemistry and Sustainability. Green Chem. 2017, 19, 18-43. 1148

(47) Romañuk, C. B.; Garro Linck, Y.; Chattah, A. K.; Monti, G. A.; 1149 Cuffini, S. L.; Garland, M. T.; Baggio, R.; Manzo, R. H.; Olivera, M. E. 1150 Crystallographic, Thermal and Spectroscopic Characterization of a 1151 Ciprofloxacin Saccharinate Polymorph. Int. J. Pharm. 2010, 391, 197- 1152 202. 1153

(48) Romañuk, C. B.; Manzo, R. H.; Garro Linck, Y.; Chattah, A. K.; 1154 Monti, G. A.; Olivera, M. E. Characterization of the Solubility and 1155 Solid-State Properties of Saccharin Salts of Fluoroquinolones. J. 1156 Pharm. Sci. 2009, 98, 3788-3801.

1157

(49) Chrzanowski, F. A.; Ahmad, K. The Preparation and Evaluation 1158 of Salt Forms of Linogliride with Reduced Solubilities as Candidates 1159 for Extended Release. Drug Dev. Ind. Pharm. 2017, 43, 421-431. 1160

(50) Surov, A. O.; Manin, A. N.; Voronin, A. P.; Drozd, K. V.; 1161 Simagina, A. A.; Churakov, A. V.; Perlovich, G. L. Pharmaceutical 1162 Salts of Ciprofloxacin with Dicarboxylic Acids. Eur. J. Pharm. Sci. 1163 2015, 77, 112-121.

(51) Sarmah, K. K.; Sarma, P.; Rao, D. R.; Gupta, P.; Nath, N. K.; 1165 Arhangelskis, M.; Thakuria, R. Mechanochemical Synthesis of 1166 Olanzapine Salts and Their Hydration Stability Study Using Powder 1167 X-Ray Diffraction. Cryst. Growth Des. 2018, 18, 2138-2150. 1168

(52) Bonyi, E.; Onuk, Z.; Constance, E.; Boone-Kukoyi, Z.; Gordon, 1169 B.; Kioko, B.; Daodu, O.; Aslan, K. Metal-Assisted and Microwave- 1170 Accelerated Evaporative Crystallization: An Approach to Rapid 1171 Crystallization of Biomolecules. CrystEngComm 2016, 18, 5600- 1172 5610.

1173

(53) Reddy, J. S.; Saraswatula Viswanadha, G.; Ravikumar, N.; 1174 Rambabu, D.; Solomon, K. A.; Kumar, K. A.; Goud, N. R.; Nangla, A. 1175 Fluoroquinolone Salts with Carboxylic Acids. J. Pharmaceutical Sci. 1176 2011, 100, 3160-3176, DOI: 10.1002/jps.22537.

1177

(54) Hiendrawan, S.; Widjojokusumo, E.; Veriansyah, B.; 1178 Tjandrawinata, R. R. Pharmaceutical Salts of Carvedilol: Poly- 1179 morphism and Physicochemical Properties. AAPS PharmSciTech 1180 2017, 18, 1417-1425.

1181

(55) Fulias, A.; Vlase, G.; Ledeti, I.; Suta, L. M. Ketoprofen-Cysteine 1182 Equimolar Salt: Synthesis, Thermal Analysis, PXRD and FTIR 1183 Spectroscopy Investigation. J. Therm. Anal. Calorim. 2015, 121, 1184 1087-1091.

(56) Panerai, A. E.; Lanata, L.; Ferrari, M.; Bagnasco, M. A New 1186 Ketoprofen Lysine Salt Formulation: 40 mg Orodispersible Granules. 1187 Trends Med. 2012, 12, 159-167.

1188

(57) Stigliani, M.; Aquino, R. P.; Del Gaudio, P.; Mencherini, T.; 1189 Sansone, F.; Russo, P. Non-Steroidal Anti-Inflammatory Drug for 1190 Pulmonary Administration: Design and Investigation of Ketoprofen 1191 Lysinate Fine Dry Powders. Int. J. Pharm. 2013, 448, 198-204. 1192 
1193 (58) Diniz, L. F.; Carvalho, P. S.; De Melo, C. C.; Ellena, J. 1194 Reducing the Hygroscopicity of the Anti-Tuberculosis Drug (S,S)1195 Ethambutol Using Multicomponent Crystal Forms. Cryst. Growth Des. 1196 2017, 17, 2622-2630.

1197 (59) Cvetkovski, A.; Ferretti, V.; Bertolasi, V. New Pharmaceutical 1198 Salts Containing Pyridoxine. Acta Crystallogr., Sect. C: Struct. Chem. 1199 2017, 73, 1064-1070.

1200 (60) Ainurofiq, A.; Mauludin, R.; Mudhakir, D.; Umeda, D.; 1201 Soewandhi, S. N.; Putra, O. D.; Yonemochi, E. Improving Mechanical 1202 Properties of Desloratadine via Multicomponent Crystal Formation. 1203 Eur. J. Pharm. Sci. 2018, 111, 65-72.

1204 (61) Wang, C.; Paul, S.; Wang, K.; Hu, S.; Sun, C. C. Relationships 1205 among Crystal Structures, Mechanical Properties, and Tableting 1206 Performance Probed Using Four Salts of Diphenhydramine. Cryst. 1207 Growth Des. 2017, 17, 6030-6040, DOI: 10.1021/acs.cgd.7b01153. 1208 (62) Hiendrawan, S.; Hartanti, A. W.; Veriansyah, B.; 1209 Widjojokusumo, E.; Tjandrawinata, R. R. Solubility Enhancement of 1210 Ketoconazole Via Salt and Cocrystal Formation. Int. J. Pharm. Pharm. 1211 Sci. 2015, 7, 160-164.

1212 (63) Derdour, L.; Reckamp, J. M.; Pink, C. Development of a 1213 Reactive Slurry Salt Crystallization to Improve Solid Properties and 1214 Process Performance and Scalability. Chem. Eng. Res. Des. 2017, 121, 1215 207-218.

1216 (64) Fernández Casares, A.; Nap, W. M.; Ten Figás, G.; Huizenga, 1217 P.; Groot, R.; Hoffmann, M. An Evaluation of Salt Screening 1218 Methodologies. J. Pharm. Pharmacol. 2015, 67, 812-822.

1219 (65) Spingler, B.; Schnidrig, S.; Todorova, T.; Wild, F. Some 1220 Thoughts about the Single Crystal Growth of Small Molecules. 1221 CrystEngComm 2012, 14, 751-757.

1222 (66) ElShaer, A.; Ouyang, D.; Hanson, P.; R, M. A. Preparation and 1223 Evaluation of Amino Acid Based Salt Forms of Model Zwitterionic 1224 Drug Ciprofloxacin. J. Pharm. Drug Delivery Res. 2013, 02, 1-10.

1225 (67) Shah, P. S.; Hanrath, T.; Johnston, K. P.; Korgel, B. A. 1226 Nanocrystal and Nanowire Synthesis and Dispersibility in Super1227 critical Fluids. J. Phys. Chem. B 2004, 108, 9574-9587.

1228 (68) Rudrangi, S. R. S.; Kaialy, W.; Ghori, M. U.; Trivedi, V.; 1229 Snowden, M. J.; Alexander, B. D. Solid-State Flurbiprofen and 1230 Methyl- $\beta$-Cyclodextrin Inclusion Complexes Prepared Using a Single1231 Step, Organic Solvent-Free Supercritical Fluid Process. Eur. J. Pharm. 1232 Biopharm. 2016, 104, 164-170.

1233 (69) Padrela, L.; Rodrigues, M. A.; Velaga, S. P.; Fernandes, A. C.; 1234 Matos, H. A.; de Azevedo, E. G. Screening for Pharmaceutical 1235 Cocrystals Using the Supercritical Fluid Enhanced Atomization 1236 Process. J. Supercrit. Fluids 2010, 53, 156-164.

1237 (70) Padrela, L.; Rodrigues, M. A.; Tiago, J.; Velaga, S. P.; Matos, H. 1238 A.; De Azevedo, E. G. Insight into the Mechanisms of Cocrystalliza1239 tion of Pharmaceuticals in Supercritical Solvents. Cryst. Growth Des. 1240 2015, 15, 3175-3181.

1241 (71) Bánsághi, G.; Székely, E.; Sevillano, D. M.; Juvancz, Z.; 1242 Simándi, B. Diastereomer Salt Formation of Ibuprofen in Supercritical 1243 Carbon Dioxide. J. Supercrit. Fluids 2012, 69, 113-116.

1244 (72) Re, M. I. Microencapsulation by Spray Drying. Drying Technol. 1245 1998, 16, 1195-1236.

1246 (73) Maas, S. G.; Schaldach, G.; Littringer, E. M.; Mescher, A.; 1247 Griesser, U. J.; Braun, D. E.; Walzel, P. E.; Urbanetz, N. A. The 1248 Impact of Spray Drying Outlet Temperature on the Particle 1249 Morphology of Mannitol. Powder Technol. 2011, 213, 27-35.

1250 (74) Jensen, K. T.; Blaabjerg, L. I.; Lenz, E.; Bohr, A.; Grohganz, H.; 1251 Kleinebudde, P.; Rades, T.; Löbmann, K. Preparation and Character1252 ization of Spray-Dried Co-Amorphous Drug-Amino Acid Salts. J. 1253 Pharm. Pharmacol. 2016, 68, 615-624.

1254 (75) Cervera, M. F.; Heinämäki, J.; de la Paz, N.; López, O.; Maunu, 1255 S. L.; Virtanen, T.; Hatanpää, T.; Antikainen, O.; Nogueira, A.; 1256 Fundora, J.; Yliruusi, J. Effects of Spray Drying on Physicochemical 1257 Properties of Chitosan Acid Salts. AAPS PharmSciTech 2011, 12, $1258637-649$.

1259 (76) Tan, D.; Loots, L.; Friščić, T. Towards Medicinal 1260 Mechanochemistry: Evolution of Milling from Pharmaceutical Solid
Form Screening to the Synthesis of Active Pharmaceutical Ingredients 1261 (APIs). Chem. Commun. 2016, 52, 7760-7781. 1262

(77) James, S. L.; Adams, C. J.; Bolm, C.; Braga, D.; Collier, P.; 1263 Friscic, T.; Grepioni, F.; Harris, K. D. M.; Hyett, G.; Jones, W.; Krebs, 1264 A.; Mack, J.; Maini, L.; Orpen, A. G.; Parkin, I. P.; Shearouse, W. C.; 1265 Steed, J. W.; Waddell, D. C. Mechanochemistry: Opportunities for 1266 New and Cleaner Synthesis. Chem. Soc. Rev. 2012, 41, 413-447. 1267

(78) Trask, A. V.; Shan, N.; Motherwell, W. D. S.; Jones, W.; Feng, 1268 S.; Tan, R. B. H.; Carpenter, K. J. Selective Polymorph Trans- 1269 formation via Solvent-Drop Grinding. Chem. Commun. 2005, No. 7, 1270 $880-882$.

1271

(79) Trask, A. V.; Haynes, D. A.; Motherwell, W. D. S.; Jones, W. 1272 Screening for Crystalline Salts via Mechanochemistry. Chem. 1273 Commun. 2006, No. 1, 51-53.

1274

(80) Hasa, D.; Jones, W. Screening for New Pharmaceutical Solid 1275 Forms Using Mechanochemistry: A Practical Guide. Adv. Drug 1276 Delivery Rev. 2017, 117, 147-161.

1277

(81) Hasa, D.; Rauber, G. S.; Voinovich, D.; Jones, W. Cocrystal 1278 Formation through Mechanochemistry: From Neat and Liquid- 1279 Assisted Grinding to Polymer-Assisted Grinding. Angew. Chem., Int. 1280 Ed. 2015, 54, 7371-7375.

1281

(82) Ledeti, A.; Vlase, G.; Vlase, T.; Circioban, D.; Dehelean, C.; 1282 Ledeti, I.; Suta, L. M. Binary Adduct Formation of Desipramine with 1283 Dicarboxylic Acids: An Instrumental Study. J. Therm. Anal. Calorim. 1284 2018, 131, 167-173.

(83) Kasten, G.; Nouri, K.; Grohganz, H.; Rades, T.; Löbmann, K. 1286 Performance Comparison between Crystalline and Co-Amorphous 1287 Salts of Indomethacin-Lysine. Int. J. Pharm. 2017, 533, 138-144. 1288

(84) Bolla, G.; Nangia, A. Novel Pharmaceutical Salts of 1289 Albendazole. CrystEngComm 2018, 20, 6394-6405. 1290

(85) Braga, D.; Chelazzi, L.; Grepioni, F.; Dichiarante, E.; Chierotti, 1291 M. R.; Gobetto, R. Molecular Salts of Anesthetic Lidocaine with 1292 Dicarboxylic Acids: Solid-State Properties and a Combined Structural 1293 and Spectroscopic Study. Cryst. Growth Des. 2013, 13, 2564-2572. 1294

(86) Bag, P. P.; Ghosh, S.; Khan, H.; Devarapalli, R.; Malla Reddy, 1295 C. Drug-Drug Salt Forms of Ciprofloxacin with Diflunisal and 1296 Indoprofen. CrystEngComm 2014, 16, 7393-7396. 1297

(87) Crawford, D. E.; Miskimmin, C. K. G.; Albadarin, A. B.; 1298 Walker, G.; James, S. L. Organic Synthesis by Twin Screw Extrusion 1299 (TSE):Continuous, Scalable and Solvent-Free. Green Chem. 2017, 19, 1300 $1507-1518$

1301

(88) Daurio, D.; Medina, C.; Saw, R.; Nagapudi, K.; Alvarez-Núñez, 1302 F. Application of Twin Screw Extrusion in the Manufacture of 1303 Cocrystals, Part I: Four Case Studies. Pharmaceutics 2011, 3, 582- 1304 600. 1305

(89) Lee, H. L.; Vasoya, J. M.; De Lima Cirqueira, M.; Yeh, K. L.; 1306 Lee, T.; Serajuddin, A. T. M. Continuous Preparation of 1:1 1307 Haloperidol-Maleic Acid Salt by a Novel Solvent-Free Method 1308 Using a Twin Screw Melt Extruder. Mol. Pharmaceutics 2017, 14, 1309 1278-1291.

1310

(90) Dhumal, R. S.; Kelly, A. L.; York, P.; Coates, P. D.; Paradkar, A. 1311 Cocrystalization and Simultaneous Agglomeration Using Hot Melt 1312 Extrusion. Pharm. Res. 2010, 27, 2725-2733.

1313

(91) Bookwala, M.; Thipsay, P.; Ross, S.; Zhang, F.; Bandari, S.; 1314 Repka, M. A. Preparation of a Crystalline Salt of Indomethacin and 1315 Tromethamine by Hot Melt Extrusion Technology. Eur. J. Pharm. 1316 Biopharm. 2018, 131, 109-119.

1317

(92) Lobmann, K.; Laitinen, R.; Grohganz, H.; Gordon, K. C.; 1318 Strachan, C.; Rades, T. Coamorphous Drug Systems: Enhanced 1319 Physical Stability and Dissolution Rate of Indomethacin and 1320 Naproxen. Mol. Pharmaceutics 2011, 8 (8), 1919-1928. 1321

(93) Tothadi, S.; Shaikh, T. R.; Dandela, R.; Vinod, C. P.; Nangia, A. 1322 K.Can We Identify Salt-Cocrystal Continuum State Using XPS? No. 1323 Cryst. Growth Des. 2020, DOI: 10.1021/acs.cgd.0c00661 1324

(94) Harris, R. K. NMR Crystallography: The Use of Chemical 1325 Shifts. Solid State Sci. 2004, 6, 1025-1037. 1326

(95) Kojima, T.; Tsutsumi, S.; Yamamoto, K.; Ikeda, Y.; Moriwaki, 1327 T. High-Throughput Cocrystal Slurry Screening by Use of in Situ 1328 
1329 Raman Microscopy and Multi-Well Plate. Int. J. Pharm. 2010, 399, $133052-59$.

1331 (96) Mukherjee, A.; Tothadi, S.; Chakraborty, S.; Ganguly, S.; 1332 Desiraju, G. R. Synthon Identification in Co-Crystals and Polymorphs 1333 with IR Spectroscopy. Primary Amides as a Case Study. 1334 CrystEngComm 2013, 15, 4640-4654.

1335 (97) Giron, D. Applications of Thermal Analysis and Coupled 1336 Techniques in Pharmaceutical Industry. J. Therm. Anal. Calorim. 1337 2002, 68, 335-357.

1338 (98) Vitez, I. M.; Newman, A. W.; Davidovich, M.; Kiesnowski, C. 1339 The Evolution of Hot-Stage Microscopy to Aid Solid-State 1340 Characterizations of Pharmaceutical Solids. Thermochim. Acta 1998, 1341 324, 187-196.

1342 (99) Kumar, A.; Kumar, S.; Nanda, A. A Review about Regulatory 1343 Status and Recent Patents of Pharmaceutical Co-Crystals. Adv. Pharm. 1344 Bull. 2018, 8, 355-363.

1345 (100) EMA. Reflection Paper on the Use of Cocrystals of Active 1346 Substances in Medicinal Products, 2015. 